
SPECTROMETRY. Please note that the manuscript has yet to undergo peer review or be formally accepted for publication. Subsequent versions of this manuscript may have slightly different content. If accepted, the final version of this manuscript will be available via the 'Peerreviewed Publication DOI' link on the right-hand side of this webpage. Please feel free to contact us - we welcome feedback. 


\section{pyisotopomer: A Python package for obtaining nitrous oxide isotopocules from isotope} ratio mass spectrometry

Colette L. Kelly, ${ }^{*}$ Cara Manning, ${ }^{2}$ Claudia Frey, ${ }^{3}$ Noah Gluschankoff, ${ }^{1}$ and Karen L. Casciotti

1. Stanford University, Department of Earth System Science, Stanford, CA 94305, USA

2. University of Connecticut, Department of Marine Sciences, Groton, CT, 06340, USA

3. Department of Environmental Science, University of Basel, Basel, Switzerland.

* Correspondence to: Colette L. Kelly (email: clkelly@stanford.edu; address: 473 Via Ortega Room 140, Stanford, CA 94305).

Keywords: Nitrous oxide, isotopomers, nitrogen stable isotopes, scrambling, Python

Abstract

RATIONALE Obtaining nitrous oxide isotopocule measurements with isotope ratio mass spectrometry (IRMS) requires measuring the $\mathrm{m} / \mathrm{z}$ ratios of the nitrous oxide $\left(\mathrm{N}_{2} \mathrm{O}\right)$ molecule as well as those of the $\mathrm{NO}^{+}$fragment ion. This measurement depends on correcting for a phenomenon referred to as "scrambling" in the ion source, whereby the $\mathrm{NO}^{+}$fragment ion contains the outer $\mathrm{N}$ atom from the $\mathrm{N}_{2} \mathrm{O}$ molecule. While descriptions of the scrambling correction exist in the literature, there has yet to be published a unified software package and method for performing this correction.

METHODS We developed a user-friendly Python package (pyisotopomer), with a MATLAB alternative, to determine two coefficients that describe scrambling in the ion source of a given IRMS, and then to use this calibration to obtain $\mathrm{N}_{2} \mathrm{O}$ isotopocule measurements.

RESULTS We assess the sensitivity of pyisotopomer to its input parameters and discuss the relevant assumptions. We show that the scrambling behavior of an IRMS can vary with time, necessitating regular calibrations. We show that to obtain a relative uncertainty in site preference of $<1 \%$, the relative uncertainty in each scrambling coefficient should be $<0.2 \%$. Finally, we present an intercalibration between two IRMS laboratories, using pyisotopomer to calculate scrambling and obtain $\mathrm{N}_{2} \mathrm{O}$ isotopocule data.

CONCLUSIONS Given these considerations, we discuss how to use this software package to obtain high-quality $\mathrm{N}_{2} \mathrm{O}$ isotopocule data from IRMS systems, including the use of appropriate reference materials and frequency of calibration. 


\section{Introduction}

Nitrous oxide $\left(\mathrm{N}_{2} \mathrm{O}\right)$ is a potent greenhouse gas, with a greenhouse gas potential approximately 265 times that of carbon dioxide, over 100 years and on a per-molecule basis. ${ }^{1,2}$ $\mathrm{N}_{2} \mathrm{O}$ is also likely to be the most important ozone depletion agent of the $21^{\text {st }}$ century, due to production of NO radicals in the stratosphere that interact destructively with ozone. ${ }^{3-6}$ Historically, the bulk stable isotopes of nitrogen and oxygen in $\mathrm{N}_{2} \mathrm{O}$ have been used to quantify its microbial cycling in soils, ${ }^{7,8}$ its destruction by photolysis and cycling in the atmosphere, ${ }^{9,10}$ and microbial cycling in the ocean. ${ }^{1-14}$ This approach often does not provide a unique solution, because the bulk nitrogen and oxygen isotope ratios of $\mathrm{N}_{2} \mathrm{O}$ depend on the isotopic composition of the substrate, as well as the isotope effects of production and consumption processes. ${ }^{14}$ Furthermore, in the context of microbial $\mathrm{N}_{2} \mathrm{O}$ cycling in soils and the ocean, bacterial nitrification and denitrification produce $\mathrm{N}_{2} \mathrm{O}$ with similar bulk $\delta^{15} \mathrm{~N}$ values, which prevents partitioning between these processes on the basis of bulk $\delta^{15} \mathrm{~N}$ alone. ${ }^{15,16}$ This leaves room for a more nuanced measurement, which may distinguish between $\mathrm{N}_{2} \mathrm{O}$ production processes in the soils, atmosphere, and ocean.

Given the asymmetry of the $\mathrm{N}_{2} \mathrm{O}$ molecule, its two nitrogen atoms exist in unique chemical environments, making the molecule particularly rich in isotopic information. The individual isotopic compositions of each nitrogen atom were first measured by Friedman and Bigeleisen, who quantified the yields of isotopomers ${ }^{14} \mathrm{~N}^{15} \mathrm{~N}^{16} \mathrm{O}$ and ${ }^{15} \mathrm{~N}^{14} \mathrm{~N}^{16} \mathrm{O}$ from enriched ammonium nitrate by measuring the ion beam signal of the fragment ion $\mathrm{NO}^{+}$in an isotope ratio mass spectrometer. ${ }^{17}$ The natural abundance isotopomers of $\mathrm{N}_{2} \mathrm{O}$ were quantified 50 years later with a similar technique, by measuring the molecular $\mathrm{N}_{2} \mathrm{O}$ mass to charge $(\mathrm{m} / \mathrm{z})$ ratios 44,45 , and 46 as well as the $\mathrm{m} / \mathrm{z}$ ratios 30 and 31 of the $\mathrm{NO}^{+}$fragment ion. ${ }^{18,19}$ Toyoda and Yoshida (1999) defined the site-specific isotope ratios of the central $(\alpha)$ nitrogen atom and outer $(\beta)$ nitrogen atom as follows:

$$
{ }^{15} R^{\alpha}=\frac{{ }^{14} N^{15} N O}{{ }^{14} N^{14} N O}
$$

$$
{ }^{15} R^{\beta}=\frac{{ }^{15} N^{14} N O}{{ }^{14} N^{14} N O}
$$

The $\mathrm{N}_{2} \mathrm{O}$ isotopomer measurement was initially performed with two sequential measurements of the same sample on an isotope ratio mass spectrometer, one for $\mathrm{m} / \mathrm{z}$ ratios 44 , 45 , and 46 , and one for $\mathrm{m} / \mathrm{z}$ ratios 30 and $31 .{ }^{18}$ Subsequent advances led to the measurement of all five $\mathrm{m} / \mathrm{z}$ ratios simultaneously with the correct configuration of cups. ${ }^{20}$

The slight difference in zero-point energies between the isotopomers of $\mathrm{N}_{2} \mathrm{O}$ result in different isotopic fractionations during photolysis in the stratosphere, ${ }^{21}$ making the isotopomers of $\mathrm{N}_{2} \mathrm{O}$ a powerful tool for understanding its atmospheric cycling. ${ }^{22-26}$ Likewise, $\mathrm{N}_{2} \mathrm{O}$ site preference, defined as $\delta^{15} \mathrm{~N}^{\alpha}-\delta^{15} \mathrm{~N}^{\beta}$, was shown in microbial culture experiments to be largely a function of reaction mechanism, independent of source composition. ${ }^{27-32}$ This allowed for the differentiation between $\mathrm{N}_{2} \mathrm{O}$ deriving from bacterial nitrification and denitrification, although some debate exists about whether the site preference of $\mathrm{N}_{2} \mathrm{O}$ produced by denitrifying bacteria is closer to $0 \%$ or $25 \%,{ }^{31,33}$ the latter possibility being largely ignored in subsequent literature. During $\mathrm{N}_{2} \mathrm{O}$ consumption, $\delta^{15} \mathrm{~N}^{\alpha}$ and $\delta^{18} \mathrm{O}_{\mathrm{N} 2 \mathrm{O}}$ were shown in microbial culture $\mathrm{e}^{34}$ and soil mesocosm ${ }^{35}$ experiments to exhibit a characteristic relationship, allowing subsequent studies to 
use this expected relationship to distinguish between oxidative and reductive regimes of $\mathrm{N}_{2} \mathrm{O}$ cycling. ${ }^{36,37}$

The site-specific isotopomers of $\mathrm{N}_{2} \mathrm{O}$ provide a far more nuanced constraint on the biogeochemical cycling of $\mathrm{N}_{2} \mathrm{O}$ than its bulk composition alone. $\mathrm{N}_{2} \mathrm{O}$ isotopomers have been used extensively to quantify its biogeochemical cycling in soils ${ }^{35,38-40}$ the atmosphere, ${ }^{22,29}$ and the ocean. ${ }^{27,36,37,41-48}$ Nonetheless, there is as yet no unified method for calibrating isotope ratio mass spectrometry systems for the $\mathrm{N}_{2} \mathrm{O}$ isotopomer (and isotopocule) measurement. The need for such a calibration is largely due to a phenomenon called "scrambling," whereby the $\mathrm{NO}^{+}$ fragment ion contains the outer, $\beta$ nitrogen atom, rather than the expected $\alpha$ nitrogen. A number of approaches have been taken to calibrate an IRMS system for this effect: the use of a single "rearrangement factor" to describe scrambling, ${ }^{18,49}$ the use of nine coefficients to describe the different fragmentation behaviors of the different isotopocules of $\mathrm{N}_{2} \mathrm{O},{ }^{50}$ and finally the use of two coefficients to describe scrambling in the ion source. ${ }^{32}$ While descriptions exist of each of these approaches, and international intercalibration efforts have been made, ${ }^{51,52}$ there has yet to be published a package of code for implementing one of the above isotopomer calibrations.

We developed a Python software package that implements the two-coefficient approach described by Frame and Casciotti (2010) to calibrate an IRMS system for scrambling and use that calibration to obtain high-quality $\mathrm{N}_{2} \mathrm{O}$ isotopocule data. To quantify the performance of the software, we tested its sensitivity to solver parameters and the assumptions inherent to the scrambling equations. Next, we quantified the uncertainty associated with different pairings of reference materials used to calculate scrambling and compared the outputs from the MATLAB and Python versions of the software. To quantify the variability of the fragmentation behavior of an instrument over time, we examined the scrambling coefficients for one isotope ratio mass spectrometer over the course of four years of measurements. To assess the effect of uncertainty in each scrambling coefficient on calculated isotopocule values, we used a Monte Carlo simulation approach to quantify the effect of uncertainty in the scrambling coefficients on the final, output $\mathrm{N}_{2} \mathrm{O}$ isotopocule values. Finally, we performed an intercalibration using this software across two labs at Stanford and the University of Basel.

\section{Theory}

Toyoda and Yoshida (1999) introduced the isotopomer notation in equations 1 and 2, designating the inner and outer nitrogen atoms as the $\alpha$ and $\beta$ nitrogen atoms, respectively. The expressions for molecular $\mathrm{m} / \mathrm{z}$ ratios $45 / 44\left({ }^{45} \mathrm{R}\right)$ and $46 / 44\left({ }^{46} \mathrm{R}\right)$, used for two different calibration approaches, ${ }^{18,49}$ follow from this notation:

$$
\begin{gathered}
{ }^{45} R={ }^{15} R^{\alpha}+{ }^{15} R^{\beta}+{ }^{17} R \\
{ }^{46} R=\left({ }^{15} R^{\alpha}+{ }^{15} R^{\beta}\right){ }^{17} R+{ }^{18} R+\left({ }^{15} R^{\alpha}\right)\left({ }^{15} R^{\beta}\right)
\end{gathered}
$$

124

125

126

127

128

129

130

where ${ }^{15} \mathrm{R}^{\alpha}$ denotes the isotopocule ratio ${ }^{14} \mathrm{~N}^{15} \mathrm{~N}^{16} \mathrm{O} /{ }^{14} \mathrm{~N}^{14} \mathrm{~N}^{16} \mathrm{O},{ }^{15} \mathrm{R}^{\beta}$ denotes the isotopocule ratio ${ }^{15} \mathrm{~N}^{14} \mathrm{~N}^{16} \mathrm{O} /{ }^{14} \mathrm{~N}^{14} \mathrm{~N}^{16} \mathrm{O},{ }^{17} \mathrm{R}$ denotes the isotopocule ratio ${ }^{14} \mathrm{~N}^{14} \mathrm{~N}^{17} \mathrm{O} /{ }^{14} \mathrm{~N}^{14} \mathrm{~N}^{16} \mathrm{O}$, and ${ }^{18} \mathrm{R}$ denotes the isotopocule ratio ${ }^{14} \mathrm{~N}^{14} \mathrm{~N}^{18} \mathrm{O} /{ }^{14} \mathrm{~N}^{14} \mathrm{~N}^{16} \mathrm{O}$.

While the oxygen triple isotopes of $\mathrm{N}_{2} \mathrm{O}\left(\Delta^{17} \mathrm{O}\right)$ provide additional information about the sources and sinks of $\mathrm{N}_{2} \mathrm{O},{ }^{53,54}$ they will not be discussed further here. Thus, we will assume that ${ }^{17} \mathrm{R}$ covaries with ${ }^{18} \mathrm{R}$ according to the oxygen isotope content of Vienna Standard Mean Ocean Water (VSMOW) ${ }^{55,56}$ and a mass-dependent relationship between ${ }^{17} \mathrm{R}$ and ${ }^{18} \mathrm{R}:{ }^{53}$ 

and Yoshida (1999):

$$
{ }^{17} R / 0.0003799=\left({ }^{18} R / 0.0020052\right)^{0.516}
$$

$$
{ }^{31} R={ }^{15} R^{\alpha}+{ }^{17} R
$$

This equation would represent the ${ }^{31} \mathrm{R}$ measured by IRMS if no scrambling occurred. Indeed, given a known ${ }^{15} \mathrm{R}^{\alpha}$ and ${ }^{17} \mathrm{R}$ for a reference gas, this equation defines the theoretical ${ }^{31} \mathrm{R}$ of that reference gas. Toyoda and Yoshida (1999) account for scrambling by defining the rearrangement factor $y$ (which was later redefined as $\gamma$ ) as "the fraction of $\mathrm{NO}^{+}$bearing the $\beta$ nitrogen of the initial $\mathrm{N}_{2} \mathrm{O}$ to the total $\mathrm{NO}^{+}$formed," to yield:

$$
{ }^{31} R=(1-\gamma){ }^{15} R^{\alpha}+\gamma^{15} \mathrm{R}^{\beta}+{ }^{17} R
$$

Kaiser et al. (2004) introduce a more complete representation of ${ }^{31} \mathrm{R}$, adding terms for ${ }^{15} \mathrm{~N}^{15} \mathrm{~N}^{16} \mathrm{O},{ }^{14} \mathrm{~N}^{15} \mathrm{~N}^{17} \mathrm{O}$, and ${ }^{15} \mathrm{~N}^{14} \mathrm{~N}^{17} \mathrm{O}$ to $\mathrm{m} / \mathrm{z}=31$, and terms for ${ }^{15} \mathrm{~N}^{14} \mathrm{~N}^{16} \mathrm{O}$ and ${ }^{14} \mathrm{~N}^{15} \mathrm{~N}^{16} \mathrm{O}$ to $\mathrm{m} / \mathrm{z}=30$ :

$$
{ }^{31} R=\frac{(1-\gamma){ }^{15} R^{\alpha}+\gamma^{15} R^{\beta}+\left({ }^{15} R^{\alpha}\right)\left({ }^{15} R^{\beta}\right)+{ }^{17} R\left(1+\gamma^{15} R^{\alpha}+(1-\gamma){ }^{15} R^{\beta}\right)}{1+\gamma^{15} R^{\alpha}+(1-\gamma){ }^{15} R^{\beta}}
$$

Note that Kaiser et al. (2004), in their Eqn. (3), use the term "s" in place of $\gamma,{ }^{15} \mathrm{R}_{1, \text { ref }}$ in

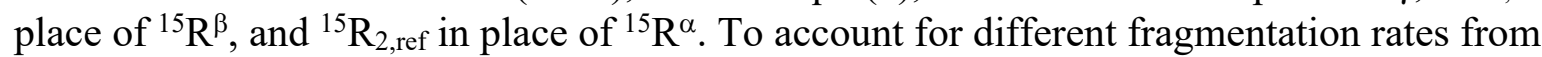
different isotopic species of $\mathrm{N}_{2} \mathrm{O}$, Westley et al. (2007) split the fragmentation factor $\gamma$ into nine coefficients:

$$
{ }^{31} R=\frac{a_{31}{ }^{15} R^{\alpha}+b_{31}{ }^{15} R^{\beta}+c_{31}\left({ }^{15} R^{\alpha}\right)\left({ }^{15} R^{\beta}\right)+{ }^{17} R\left(d_{31}+e_{31}{ }^{15} R^{\alpha}+f_{31}{ }^{15} R^{\beta}\right)}{1+a_{30}{ }^{15} R^{\alpha}+b_{30}{ }^{15} R^{\beta}+c_{30}\left({ }^{15} R^{\alpha}\right)\left({ }^{15} R^{\beta}\right)}
$$

While this approach considers the possibility of different rates of fragmentation for every isotopic species of $\mathrm{N}_{2} \mathrm{O}$ (i.e., isotopic fractionation) measurable with this IRMS configuration, it also requires solving for six to nine coefficients, depending on whether the $\mathrm{m} / \mathrm{z}=30$ coefficients are considered separate from the $\mathrm{m} / \mathrm{z}=31$ coefficients. Frame and Casciotti (2010) simplify this equation by reducing the number of fragmentation factors to two coefficients, $\gamma$ and $\kappa$, which represent the yield of ${ }^{30} \mathrm{NO}^{+}$from ${ }^{14} \mathrm{~N}^{15} \mathrm{NO}$ (for both ${ }^{17} \mathrm{O}$ and ${ }^{16} \mathrm{O}$ ) and the yield of ${ }^{31} \mathrm{NO}^{+}$from ${ }^{15} \mathrm{~N}^{14} \mathrm{NO}$, respectively. This yields the equation:

$$
{ }^{31} R=\frac{(1-\gamma){ }^{15} R^{\alpha}+\kappa{ }^{15} R^{\beta}+\left({ }^{15} R^{\alpha}\right)\left({ }^{15} R^{\beta}\right)+{ }^{17} R\left(1+\gamma^{15} R^{\alpha}+(1-\kappa){ }^{15} R^{\beta}\right)}{1+\gamma^{15} R^{\alpha}+(1-\kappa){ }^{15} R^{\beta}}
$$

The important pieces of information contained within the two scrambling factors are the unequal rates of fragmentation for the isotopomers ${ }^{14} \mathrm{~N}^{15} \mathrm{NO}$ and ${ }^{15} \mathrm{~N}^{14} \mathrm{NO}$, which the equation from Kaiser et al. (2004) does not account for. It is assumed that the isotopic substitution of ${ }^{17} \mathrm{O}$ in the oxygen atom has a negligible effect on the scrambling coefficients, or, in terms of the 
equation from Westley et al. (2007), that $e_{31}=\left(1-a_{31}\right)$ and $f_{31}=\left(1-b_{31}\right)$. It is also assumed that the coefficient $c_{31}$ from Westley et al. (2007) is equal to 1 , or that the yield of ${ }^{31} \mathrm{NO}^{+}$from ${ }^{15} \mathrm{~N}^{15} \mathrm{~N}^{16} \mathrm{O}$ is equal to the yield of ${ }^{30} \mathrm{NO}^{+}$from ${ }^{14} \mathrm{~N}^{14} \mathrm{~N}^{16} \mathrm{O}$. Given that naturally occurring $\mathrm{N}_{2} \mathrm{O}$ contains very little of the ${ }^{15} \mathrm{~N}^{15} \mathrm{~N}^{16} \mathrm{O}$ isotopocule, a few per mil difference in the fractionation during fragmentation of ${ }^{15} \mathrm{~N}^{15} \mathrm{~N}^{16} \mathrm{O}$ and ${ }^{14} \mathrm{~N}^{14} \mathrm{~N}^{16} \mathrm{O}$ would not drastically alter the measured ${ }^{31} \mathrm{R} .{ }^{57}$ Finally, the coefficient $d_{31}$ is assumed to be equal to 1 , or that the yield of ${ }^{31} \mathrm{NO}^{+}$from ${ }^{14} \mathrm{~N}^{14} \mathrm{~N}^{17} \mathrm{O}$ is equal to the yield of ${ }^{30} \mathrm{NO}^{+}$from ${ }^{14} \mathrm{~N}^{14} \mathrm{~N}^{16} \mathrm{O}$, again, an assumption yielding little potential error in ${ }^{31} \mathrm{R}$, given the low natural abundance of ${ }^{17} \mathrm{O}$ in $\mathrm{N}_{2} \mathrm{O} .{ }^{53}$

Measurement of two reference materials against a common third reference gas, each with known ${ }^{15} R^{\alpha}$ and ${ }^{15} R^{\beta}$ values, produces two equations to solve for two unknowns, $\gamma$ and $\kappa$,

$$
\frac{{ }^{31} R_{\text {sample } 1}}{{ }^{31} R_{\text {reference }}}-\frac{\left[r R 31 / 30_{\text {sample } 1}\right]}{\left[r R 31 / 30_{\text {reference }}\right]}=0
$$

$$
\frac{{ }^{31} R_{\text {sample } 2}}{{ }^{31} R_{\text {reference }}}-\frac{\left[r R 31 / 30_{\text {sample } 2}\right]}{\left[r R 31 / 30_{\text {reference }}\right]}=0
$$

Where ${ }^{31} \mathrm{R}_{\text {sample } 1}$ is the theoretical ${ }^{31} \mathrm{R}$ of the first reference material, calculated from equation $10,{ }^{31} \mathrm{R}_{\text {reference }}$ is the theoretical ${ }^{31} \mathrm{R}$ of the common reference gas against which sample peaks are normalized, and ${ }^{31} \mathrm{R}_{\text {sample } 2}$ is the theoretical ${ }^{31} \mathrm{R}$ of the second reference material. These "ratios of ratios" should be equivalent to the measured ${ }^{31} \mathrm{R}$ of each reference material normalized to the common reference injection, leaving a set of cost functions to be minimized. To aid in finding a solution, equations 11 and 12 may be simplified by assuming that the ${ }^{31} \mathrm{R}$ of the direct reference injection is constant ("C", below), and thus that the flat-topped reference peak has a defined scrambling behavior that could differ from that of a sample peak. Calculating ' $\mathrm{C}$ ' for the common reference injection from equation 10, using assumed $\gamma$ and $\kappa$ values, produces the following two equations:

$$
\frac{{ }^{31} R_{\text {sample } 1}}{C}-\frac{\left[r R 31 / 30_{\text {sample } 1}\right]}{\left[r R 31 / 30_{\text {reference }}\right]}=0
$$

$$
\frac{{ }^{31} R_{\text {sample } 2}}{C}-\frac{\left[r R 31 / 30_{\text {sample } 2}\right]}{\left[r R 31 / 30_{\text {reference }}\right]}=0
$$

\section{Given a pair of reference materials with known ${ }^{15} \mathrm{R}^{\alpha}$ and ${ }^{15} \mathrm{R}^{\beta}$, pyisotopomer ${ }^{58}$ solves} equations 13 and 14 for scrambling coefficients $\gamma$ and $\kappa$. Pyisotopomer uses the "least_squares" function from the scipy optimization library to vary $\gamma$ and $\kappa$ until the calculated values of ${ }^{31} \mathrm{R}_{\text {sample }} /{ }^{31} \mathrm{R}_{\text {reference }}$ are as close to $[\mathrm{rR} 31 \mathrm{NO} / 30 \mathrm{NO}$ sample $/ \mathrm{R} 31 \mathrm{NO} / 30 \mathrm{NO}$ reference], as described in Frame and Casciotti (2010). In MATLAB, the solver lsqnonlin is used to perform the optimization.

After the scrambling coefficients are calculated from measured reference materials, pyisotopomer can be used to calculate the ${ }^{15} \mathrm{R}^{\alpha}$ and ${ }^{15} \mathrm{R}^{\beta}$ of unknown samples using equations 3 , 4 , and 10. These equations are solved for the ${ }^{15} \mathrm{R}^{\alpha}$ and ${ }^{15} \mathrm{R}^{\beta}$, from measured isotope ratios ${ }^{31} \mathrm{R}$, ${ }^{45} \mathrm{R}$, and ${ }^{46} \mathrm{R}$ of the unknown. As in the scrambling function, pyisotopomer uses least_squares from scipy.optimize to solve this set of equations, producing the isotope ratios ${ }^{15} \mathrm{R}^{\alpha},{ }^{15} \mathrm{R}^{\beta},{ }^{17} \mathrm{R}$, 
and ${ }^{18} \mathrm{R}$, and from these, the delta values $\delta^{15} \mathrm{~N}^{\alpha}, \delta^{15} \mathrm{~N}^{\beta}$, site preference, $\delta^{15} \mathrm{~N}^{\text {bulk }}, \delta^{17} \mathrm{O}_{\mathrm{N} 2 \mathrm{O}}$, and $\delta^{18} \mathrm{O}_{\mathrm{N} 2 \mathrm{O}}$ are calculated relative to primary reference scales $\left({ }^{15} \mathrm{R}\right.$ from atmospheric $\mathrm{N}_{2}$ and ${ }^{17} \mathrm{R}$ and $199 \quad{ }^{18} \mathrm{R}$ from VSMOW).

\section{Experimental}

\subsection{Preparation and analysis of $\mathrm{N}_{2} \mathrm{O}$ reference materials}

To validate the usage of pyisotopomer to calculate scrambling coefficients, and from these coefficients obtain precise $\mathrm{N}_{2} \mathrm{O}$ isotopocule data, a series of $\mathrm{N}_{2} \mathrm{O}$ reference materials (Table 1) were prepared and analyzed in sample format at Stanford University ("Lab 1") and the University of Basel ("Lab 2"). Reference materials were prepared by filling $160-\mathrm{mL}$ glass serum bottles (Wheaton) with de-ionized water and removing a 4-mL headspace (Lab 1) or 10-20-mL headspace (Lab 2), then were capped with a gray butyl septum (National Scientific) and sealed with an aluminum crimp seal. These bottles were purged with helium for 90 minutes to remove all background $\mathrm{N}_{2} \mathrm{O}$. The purged bottles were then injected with reference gas in a range of nmol amounts from 2-20 nmols $\mathrm{N}_{2} \mathrm{O}$ (S2, EMPA1, EMPA2, EMPA3 reference gases) or with 10 nmols $\mathrm{N}_{2} \mathrm{O}$ (B6 reference gas) using a gas-tight syringe. Reference materials prepared in Lab 1 were preserved with $100 \mu \mathrm{L}$ saturated mercuric chloride solution; those prepared in Lab 2 contained no added preservative. For Lab 1, atmosphere-equilibrated seawater was prepared by filtering surface seawater (collected in Half Moon Bay, CA) through a $0.22 \mathrm{~mm}$ Sterivex filter, allowing it to undergo static equilibration with outdoor air for three days, then re-filtering into $160-\mathrm{mL}$ serum bottles, removing a $\sim 1$-mL headspace, and preserving with $100 \mu \mathrm{L}$ saturated mercuric chloride solution. For Lab 2, atmosphere-equilibrated reference materials were prepared by purging either de-ionized water or a sodium chloride solution with helium, allowing it to undergo static equilibration with outdoor air for three days, filling into $160-\mathrm{mL}$ serum bottles, and removing a $10-\mathrm{mL}$ headspace. Reference materials were run in the same format as samples to account for any potential fractionation associated with the extraction and purification of $\mathrm{N}_{2} \mathrm{O}$ associated with the purge-and-trap system. The magnitude of such fractionation was quantified for Lab 1 by running the pure $\mathrm{N}_{2} \mathrm{O}$ reference tank against itself, and yielded offsets of $0.22 \pm 0.52 \%$ for $\delta^{15} \mathrm{~N}^{\text {bulk }}$ and $0.16 \pm 0.62 \%$ for $\delta^{18} \mathrm{O}_{\mathrm{N} 2 \mathrm{O}}$.

The isotopocule values for each reference gas were calibrated independently by J. Mohn (EMPA; mini-QCLAS aerodyne) or S. Toyoda (Tokyo Tech; IRMS), except for one internal standard used by Lab 1 (Table 1). The reported ${ }^{31} \mathrm{R},{ }^{45} \mathrm{R}$, and ${ }^{46} \mathrm{R}$ for the pure $\mathrm{N}_{2} \mathrm{O}$ reference tanks represent the theoretical values of these ratios, assuming some amount of scrambling for the reference gas: $\gamma=0.17$ and $\kappa=0.08$ (Stanford University/Lab 1), and $\gamma=0.156$ and $\kappa=0.155$ (University of Basel/Lab 2). The values for $\delta^{17} \mathrm{O}_{\mathrm{N} 2 \mathrm{O}}$ for each gas were calculated assuming a mass-dependent relationship between ${ }^{17} \mathrm{R}$ and ${ }^{18} \mathrm{R} .{ }^{53}$

These reference gases and samples were measured on Thermo Finnigan DELTA $V^{\text {PLUS }}$ isotope ratio mass spectrometers (IRMS; Thermo Fisher Scientific, Waltham, MA) in Lab 1 and Lab 2. Each IRMS had Faraday cups configured to simultaneously measure $m / z$ 30, 31, 44, 45, and 46. Reference materials and samples were analyzed on a custom purge-and-trap system coupled to each IRMS, which was run in continuous flow mode ${ }^{59}$ (Table 1). The two systems had slight differences in the purge-and-trap system: in Lab 1, liquid from each sample bottle was transferred to a sparging column to extract the dissolved gases; in Lab 2, each sample was extracted by purging directly from the bottle. The effects of these differences are discussed further in Results and Discussion. 


\subsection{Data corrections}

To calibrate each IRMS for scrambling, reference materials prepared as above were run

from pyisotopomer import Scrambling, Isotopomers

Scrambling(inputfile="FILENAME.xlsx", ref1="NAME", ref2="NAME", **kwargs)

To calculate scrambling, the only function you need is:

278 side-by-side on the same day. This was repeated over multiple days. From these runs, a scrambling calibration was obtained as follows: first, each sample peak was compared against a direct injection of pure $\mathrm{N}_{2} \mathrm{O}$ from a reference tank (Table 1). ${ }^{60}$ Next, sample peaks were normalized to a peak area of 20 Volt-seconds (Vs) to correct for the effect of peak size on measured isotope ratios. This normalization was performed with a linearity relation specific to each IRMS and purge-and-trap system. ${ }^{37}$ Then, for each day of analysis, pyisotopomer was used to generate all possible pairings of reference materials on that day. Each pairing of reference materials and the associated size-corrected isotope ratios were used as an input to the Scrambling function of pyisotopomer to calculate a pair of $\gamma$ and $\kappa$, the scrambling coefficients introduced in Eqn. (10). From the resulting array of $\gamma$ and $\kappa$ values, $\gamma$ and $\kappa$ were averaged to obtain a daily mean. These daily means were further combined into a one-week running average to smooth their variability. The one-week running averages of $\gamma$ and $\kappa$ for each system were used to obtain $\mathrm{N}_{2} \mathrm{O}$ isotopocules for reference materials and unknowns, using the Isotopomers function of pyisotopomer. Finally, a scale decompression (similar to the two-point offset correction suggested by Mohn et al., 2014) was performed for $\delta^{15} \mathrm{~N}^{\alpha}, \delta^{15} \mathrm{~N}^{\beta}, \delta^{17} \mathrm{O}_{\mathrm{N} 2 \mathrm{O}}$, and $\delta^{18} \mathrm{O}_{\mathrm{N} 2 \mathrm{O}}$, based on the mean measured values and calibrated values of the reference materials included in each run. The scale-decompressed values of $\delta^{15} \mathrm{~N}^{\text {bulk }}$ and SP were obtained from the scale-decompressed $\delta^{15} \mathrm{~N}^{\alpha}$ and $\delta^{15} \mathrm{~N}^{\beta}$.

The data corrections above are described in the README documents associated with pyisotopomer on the Python Package Index. In brief, comparison against the direct $\mathrm{N}_{2} \mathrm{O}$ reference injection and normalization to a peak area of $20 \mathrm{Vs}$ can be accomplished with the appropriate IRMS outputs and the pyisotopomer data input template. ${ }^{58}$ The import convention for pyisotopomer is:

where "FILENAME.xlsx" is the user-designated file name of the data corrections spreadsheet to be used as the inputfile, "ref1" and "ref2" are the reference materials used to perform the scrambling calibration designated with their user-entered "NAME"s, and "**kwargs" refers to optional additional keyword arguments, such as the initial guess for $\gamma$ and $\kappa$ (see section 4.1). Once the scrambling coefficients are determined, the only function needed to calculate isotopomers is: 
Isotopomers(inputfile $=$ "FILENAME.xlsx", scrambling $=[0.0 \ldots, 0.0 \ldots], * *$ kwargs $)$

where "scrambling" refers to the scrambling coefficients used to calculate isotopomers.

\subsection{Intercalibration}

To validate the scrambling calibration, samples of unknown isotopic composition were collected from Lake Lugano, Switzerland in July 2020 and analyzed separately by both Lab 1 and Lab 2. The samples were collected at depths of 10 and 90 meters, including six replicate bottles at each depth. Samples were collected into 160-mL glass serum bottles (Wheaton), overflowing each bottle twice, closing bubble-free, and removing liquid to form a $10-\mathrm{mL}$ headspace comprised of air. Based on the Northern hemisphere monthly mean $\mathrm{N}_{2} \mathrm{O}$ mixing ratio for July, 2020, ${ }^{61}$ when the samples were collected, an atmospheric headspace of this volume would have contained 0.13 nmols $\mathrm{N}_{2} \mathrm{O}$, and resulted in a $\sim 1 \mathrm{nM}$ overestimation of the concentration of $\mathrm{N}_{2} \mathrm{O}$ in each sample after equilibration with the headspace during storage. Each sample was capped with a gray butyl septum (National Scientific) and sealed with an aluminum crimp seal. Samples were promptly preserved with $100 \mu \mathrm{L}$ saturated mercuric chloride solution and stored at lab temperature $\left(20-22^{\circ} \mathrm{C}\right)$. Given the trace amount of $\mathrm{N}_{2} \mathrm{O}$ in the atmosphere, negligible amount of atmospheric $\mathrm{N}_{2} \mathrm{O}$ were added with the $100 \mu \mathrm{L}$ of mercuric chloride, and with complete flushing of the bottle during analysis, the effect of the headspace and $\mathrm{N}_{2} \mathrm{O}$ partitioning between the gas and liquid phases falls within the analytical uncertainty for $\mathrm{N}_{2} \mathrm{O}$ concentration and isotopocule measurements. ${ }^{37}$ The six replicate bottles at each depth were split into two groups of three replicate bottles to be measured for $\mathrm{N}_{2} \mathrm{O}$ isotopocules by Lab 1 and Lab 2 , respectively. The scrambling calibration and isotopocule calculations for each set of samples were performed in pyisotopomer, as above.

\section{Results and Discussion 4.1 Solver parameters}

To understand the sensitivity of the Scrambling function of pyisotopomer to the parameters provided to its solver (initial guess, upper bound, lower bound), we performed a series of numerical experiments with said solver. The first of these experiments involved varying the initial guess, $\mathrm{x} 0$ (where $\mathrm{x} 0$ is a pair of values for $\gamma$ and $\kappa$ ). Using a range of 50 initial guesses for $\gamma$ and $\kappa$, evenly spaced between $\gamma=\kappa=0.05$ and $\gamma=\kappa=0.20$, scrambling was calculated from four reference materials run in December 2020 on the Lab 1 IRMS. These initial guesses for $\gamma$ and $\kappa$ were varied in tandem, such that $\gamma$ and $\kappa$ were always initialized at the same value. The solver was subsequently used to obtain a range of 50 solutions for $\gamma$ and $\kappa$ corresponding to each of the 50 values of $x 0$, holding the lower bounds for the solver constant at $\gamma=0.0$ and $\kappa=0.0$ and the upper bounds constant at $\gamma=1.0$ and $\kappa=1.0$. Using the Isotopomers function of pyisotopomer, these 50 solutions for $\gamma$ and $\kappa$ were input as scrambling coefficients to obtain a range of 50 values of $\delta^{15} \mathrm{~N}^{\alpha}, \delta^{15} \mathrm{~N}^{\beta}$, and SP for each of the four reference materials (Table 2).

The range of $\mathrm{x} 0$ values tested produced a similar range of solutions for $\gamma$ and $\kappa$ (Figure S1), although their solutions exhibited a nearly constant offset of $\sim 0.09$ ( $\gamma$ and $\kappa$ are unitless since they are proportions, but they can be understood as percentages, whereby a $\gamma$ value of 0.20 can be understood to mean that $20 \%$ of ${ }^{14} \mathrm{~N}^{15} \mathrm{NO}$ undergoing fragmentation yields ${ }^{30} \mathrm{NO}^{+}$instead of ${ }^{31} \mathrm{NO}^{+}$). The solutions for $\gamma$ and $\kappa$ increased as $\mathrm{x} 0$ increased, such that the initial guess $\gamma=0.05$ 
and $\kappa=0.05$ yielded the solution $\gamma=0.138$ and $\kappa=0.0454$, and the initial guess $\gamma=0.20$ and $\kappa=0.20$ yielded the solution $\gamma=0.272$ and $\kappa=0.182$ (Figure S1). Despite the wide range of solutions for $\gamma$ and $\kappa$, when used as scrambling coefficients to calculate isotopocule ratios these solutions yielded nearly constant $\delta^{15} \mathrm{~N}^{\alpha}, \delta^{15} \mathrm{~N}^{\beta}$, and SP values for the four test reference materials (Table 2). The standard deviations of $\delta^{15} \mathrm{~N}^{\alpha}$ and $\delta^{15} \mathrm{~N}^{\beta}$ were no greater than $0.07 \%$, and the standard deviation of SP was no greater than $0.13 \%$ (Table 2). The calculated $\delta^{15} \mathrm{~N}^{\text {bulk }}$ and $\delta^{18} \mathrm{O}_{\mathrm{N} 2 \mathrm{O}}$ had a standard deviation of $0.0 \%$ since they are unaffected by scrambling. This indicates that the parameter best constrained by the scrambling calculation is not the absolute value of $\gamma$ or $\kappa$, but rather their relationship to each other, and that it is this relationship that is uniquely determined by each pair of reference materials and IRMS.

Additional numerical experiments were conducted to test the sensitivity of the scrambling solver to the upper and lower bounds provided to it. The lower bounds for both $\gamma$ and $\kappa$ were varied from $\gamma=0.0$ and $\kappa=0.0$ to $\gamma=0.08$ and $\kappa=0.08$, to yield a range of 50 lower bound inputs. For these experiments, the initial guesses for $\gamma$ and $\kappa$ were held constant at $\gamma=0.17$ and $\kappa=0.08$ (standard values for Lab 1) across the range of tested lower bound values. Likewise, the upper bounds for $\gamma$ and $\kappa$ were held constant at $\gamma=1.0$ and $\kappa=1.0$ for the lower bound tests. Varying the lower bounds input to the solver resulted in a much smaller range of solutions than varying $\mathrm{x} 0$ : with the lower bounds set to $\gamma=0.0$ and $\kappa=0.0$, the solver yielded $\gamma=0.172$ and $\kappa=0.0798$; with the lower bounds set to $\gamma=0.08$ and $\kappa=0.08$, the solver yielded $\gamma=0.172$ and $\kappa=0.0800$. Again, the difference between $\gamma$ and $\gamma-\kappa$ was consistently $\sim 0.09$. It should be noted here that the range of lower bounds was smaller than the range of $\mathrm{x} 0$ in the analogous experiment above, because the lower bounds for $\gamma$ and $\kappa$ cannot, by definition, exceed the lowest value at which either coefficient is initialized - in this case, 0.08. Using the resulting range of solutions for $\gamma$ and $\kappa$ to calculate isotopocules for the four test reference materials, we found that the standard deviations of $\delta^{15} \mathrm{~N}^{\alpha}$ and $\delta^{15} \mathrm{~N}^{\beta}$ were no greater than $0.0002 \%$, and the standard deviation of SP was no greater than $0.0004 \%$ (Table 2).

Repeating this procedure to test the sensitivity of the scrambling solver to its upper bounds yielded similar results. Holding $\mathrm{x} 0$ constant at $\gamma=0.17$ and $\kappa=0.08$ and the lower bounds constant at $\gamma=0.0$ and $\kappa=0.0$, the upper bounds were varied from $\gamma=0.4$ and $\kappa=0.4$ to $\gamma=1.0$ and $\kappa=1.0$ across an array of 50 upper bound inputs. The upper bounds $\gamma=0.4$ and $\kappa=0.4$ yielded the solutions $\gamma=0.171$ and $\kappa=0.0795$, and the upper bounds $\gamma=1.0$ and $\kappa=1.0$ yielded the solutions $\gamma=0.172$ and $\kappa=0.0798$. From these results, it becomes apparent that the solutions for $\gamma$ and $\kappa$ relate more closely to the $\mathrm{x} 0$ values $\gamma=0.17$ and $\kappa=0.08$ than they relate to either the lower or upper bounds input to the solver. In this case, the upper bounds are varied from 0.4 to 1.0 to represent a reasonable range of values - unsurprisingly, the edge case wherein the upper bounds are equal or very close to the initial guesses for $\gamma$ and $\kappa$ yields solutions for each coefficient that converge at the upper boundary (not shown). Using the resulting range of $\gamma$ and $\kappa$ from varying the upper bounds to calculate isotopocules for the four test reference materials, we found that the standard deviations of $\delta^{15} \mathrm{~N}^{\alpha}$ and $\delta^{15} \mathrm{~N}^{\beta}$ were no greater than $0.002 \%$, and the standard deviation of SP was no greater than $0.005 \%$ (Table 2). The higher standard deviations in this experiment, compared to the lower bounds experiment, can be attributed to the wider range of input values.

From this set of experiments, we can provide three recommendations. Firstly, it may be useful to iterate through the scrambling calculation twice if scrambling coefficients have never been obtained for the given system before. The solution from the first iteration may be used as the initial guess for subsequent iterations, such that the initial guesses for $\gamma$ and $\kappa$ are as close to 
their solved values as possible. This can be accomplished with the "initialguess" argument to the

Scrambling(inputfile="FILENAME.xlsx", ref1="NAME", ref2="NAME", initialguess=[0.0 $0.0 \ldots])$

Secondly, we recommend setting the lower bounds for the scrambling solver to $\gamma=\kappa=0.0$, representing $0 \%$ scrambling for ${ }^{14} \mathrm{~N}^{15} \mathrm{NO}$ and ${ }^{15} \mathrm{~N}^{14} \mathrm{NO}$, respectively. Likewise, we recommend setting the upper bounds to $\gamma=\kappa=1.0$, representing $100 \%$ scrambling for ${ }^{14} \mathrm{~N}^{15} \mathrm{NO}$ and ${ }^{15} \mathrm{~N}^{14} \mathrm{NO}$, respectively. These are the defaults for pyisotopomer. We recommend these as the bounds to allow the scrambling solver to search for solutions across the widest possible range of plausible solutions (it wouldn't make sense to have negative scrambling coefficients, and neither would it makes sense to have scrambling coefficients greater than 1) and thus to avoid converging at a boundary. Our third and final recommendation is to carefully consider the bounds of ${ }^{15} \mathrm{R}^{\alpha}$ and ${ }^{15} \mathrm{R}^{\beta}$ provided to the Isotopomers solver. The default upper bounds are ${ }^{15} \mathrm{R}^{\alpha}={ }^{15} \mathrm{R}^{\beta}=1.00$, but they can be set to lower ratios such as ${ }^{15} \mathrm{R}^{\alpha}={ }^{15} \mathrm{R}^{\beta}=0.005$ in the example below, corresponding to $\delta^{15} \mathrm{~N}^{\alpha}=\delta^{15} \mathrm{~N}^{\beta}=360 \%$. This is a reasonable ceiling for natural abundance $\mathrm{N}_{2} \mathrm{O}$ measurements, but may artificially constrain ${ }^{15} \mathrm{R}^{\alpha}$ and ${ }^{15} \mathrm{R}^{\beta}$ in ${ }^{15} \mathrm{~N}$-labelled samples. Thus, is important to consider the context and type of sample when changing default arguments.

Isotopomers $($ inputfile $=$ "FILENAME.xlsx", scrambling $=[0.0 \ldots, 0.0 \ldots]$, lowerbounds $=[0.002$, 0.002], upperbounds $=[0.005,0.005])$

\subsection{Reference injection scrambling}

To aid in the optimization process, it is assumed that the flat-topped reference peak could have a slightly different $\gamma$ and $\kappa$ from the triangular sample peak. Using Eqn. (10), constant values of $\gamma$ and $\kappa$ are used to calculate the ${ }^{31} \mathrm{R}$ of the pure $\mathrm{N}_{2} \mathrm{O}$ reference gas from its calibrated $\delta^{15} \mathrm{~N}^{\alpha}$ and $\delta^{15} \mathrm{~N}^{\beta}$ (Table 1) and $\delta^{17} \mathrm{O}$ values. This ${ }^{31} \mathrm{R}$ of the pure $\mathrm{N}_{2} \mathrm{O}$ reference gas is used as the "C" parameter in Eqns. (13) and (14) and is assumed to be constant. To test the sensitivity of pyisotopomer to this assumption, the ${ }^{31} \mathrm{R}$ of the pure $\mathrm{N}_{2} \mathrm{O}$ reference gas was re-calculated across a range of $\gamma$ and $\kappa$ using Eqn. (10), then substituted into the " $\mathrm{C}$ " parameter in equations 13 and 14. This range of " $\mathrm{C}$ " was combined with the measured isotope ratios for one atmosphereequilibrated seawater and one S2 reference gas run on the Lab 1 IRMS to calculate $\gamma$ and $\kappa$ with the Scrambling function of pyisotopomer. Through this sensitivity test, each theoretical $\gamma$ and $\kappa$ for the pure $\mathrm{N}_{2} \mathrm{O}$ reference gas (C) was paired with a calculated $\gamma$ and $\kappa$ for the instrument based on the paired reference materials (Figure 1).

The calculated $\gamma$ and $\kappa$ varied linearly with the theoretical $\gamma$ and $\kappa$ for the direct reference injection (Figure 1). Varying the reference injection $\gamma$ from 0.17 to 0.18 and holding the reference injection $\kappa$ constant at 0.080 (white points in Figure 1) resulted in $\gamma$ ranging from 0.172 to 0.181 (Figure 1A) and $\kappa$ ranging from 0.080 to 0.079 (Figure 1B). Likewise, holding the 
reference injection $\gamma$ constant at 0.17 and varying the reference injection $\kappa$ from 0.080 to 0.070 (gray points in Figure 1) also resulted in $\gamma$ ranging from 0.172 to 0.181 and $\kappa$ ranging from 0.080 to 0.079 . Varying the reference injection $\gamma$ from 0.17 to 0.18 and varying the reference injection $\kappa$ from 0.080 to 0.070 (black points in Figure 1) resulted in $\gamma$ ranging from 0.172 to 0.190 and $\kappa$ ranging from 0.080 to 0.078 .

Next, the isotopocules for each reference material were calculated from each pairing of theoretical and calculated $\gamma$ and $\kappa$. Despite the variations in the calculated $\gamma$ and $\kappa$ shown in Figure 1, the resulting isotopocule ratios varied by less than $0.3 \%$ (Table 2 ). The standard deviations of $\delta^{15} \mathrm{~N}^{\alpha}$ and $\delta^{15} \mathrm{~N}^{\beta}$ were $0.13 \%$ or both the atmosphere-equilibrated seawater and $\mathrm{S} 2$ reference materials, and the standard deviation of SP was $0.27 \%$ for both reference materials (Table 2). This result indicates that the $\gamma$ and $\kappa$ solutions output by pyisotopomer compensate implicitly for the $\gamma$ and $\kappa$ assumed for the direct reference injection. Thus, we conclude that the assumption of different scrambling for the flat-topped reference peak and triangular sample peak has a small effect on the calculated isotopocules.

\subsection{Choosing reference material pairings}

To understand the effect of different pairings of reference materials on the outcome of the scrambling calibration, $\gamma$ and $\kappa$ were calculated from a collection of reference pairings run over two days. On the Lab 1 IRMS, these pairings included the "S2" and "B6" reference materials, as well as atmosphere-equilibrated seawater $\mathrm{N}_{2} \mathrm{O}$ (Table 1), the calibrated isotopocule ratios of which fall within the range of values produced in culture ${ }^{34,62}$ and nature. ${ }^{42,46}$ The mean and standard deviation of $\gamma$ and $\kappa$ were calculated from each of three possible pairings of reference materials: atmosphere-equilibrated seawater and S2 $(n=8)$, atmosphere-equilibrated seawater and B6 $(n=6)$, and S2 and B6 $(n=6)$. Reference material isotopocules were then re-calculated with the mean $\gamma$ and $\kappa$ from each pairing. Finally, a pooled standard deviation, calculated as the square root of the average of the squared standard deviations, ${ }^{63}$ was calculated from the three sets of scrambling coefficients and isotopocule values (Table S1). The same procedure was performed with three sets of $\mathrm{N}_{2} \mathrm{O}$ reference materials ("EMPA1", "EMPA2", and "EMPA3") prepared and run on the Lab 2 IRMS. Unlike the reference materials run in Lab 1, however, one of the Lab 2 reference materials ("EMPA2") had a $\delta^{15} \mathrm{~N}^{\beta}$ value (94.44\%o) much higher than what is found in culture $^{34,62}$ or nature. ${ }^{42,46}$ Again, the mean and standard deviation of $\gamma$ and $\kappa$ were calculated from each of three possible pairings: EMPA1 and EMPA2 $(n=37)$, EMPA1 and EMPA3 $(n=37)$, and EMPA2 and EMPA3 $(n=34)$. The greater number of pairings is due to a greater number of reference materials run per day. Pooled standard deviations were then calculated for $\gamma$ and $\kappa$ as well as isotopocule values (Table S1).

The pooled standard deviations of $\gamma$ and $\kappa$ calculated from the Lab 1 reference materials were 0.0007 and 0.0001 , respectively, which correspond to relative uncertainties of $0.39 \%$ and $0.16 \%$ (Table S1). T-tests between pairings of reference materials yielded no significant differences in $\gamma$ and $\kappa$. The pooled standard deviations of $\delta^{15} \mathrm{~N}^{\alpha}, \delta^{15} \mathrm{~N}^{\beta}$, and SP were all less than 1\%o (Table S1). The pooled standard deviations of $\gamma$ and $\kappa$ calculated from the Lab 2 reference materials were larger, corresponding to relative uncertainties of $0.77 \%$ and $1.17 \%$ in $\gamma$ and $\kappa$, respectively. This was mostly due to the inclusion of the EMPA2 reference gas - calculating scrambling from just the EMPA1 and EMPA3 reference gases, which did not have extreme values, resulted in relative uncertainties in $\gamma$ and $\kappa$ of $0.15 \%$ and $0.61 \%$, respectively. T-tests between pairings of reference materials yielded significant differences between the scrambling 
coefficients calculated from pairings including the EMPA2 reference gas and those without. The inclusion of the EMPA2 reference gas resulted in pooled standard deviations of $\delta^{15} \mathrm{~N}^{\alpha}, \delta^{15} \mathrm{~N}^{\beta}$ of greater than 2\%o and a pooled standard deviation of SP greater than 4\%o (Table S1).

Based on these results, we suggest that calculated $\gamma$ and $\kappa$ have a dependence on the reference materials used to solve for these parameters, the magnitude of which increases with increasingly extreme values of $\delta^{15} \mathrm{~N}^{\alpha}$ and $\delta^{15} \mathrm{~N}^{\beta}$. Thus, we caution against using reference materials with values that go far beyond bracketing the unknowns to be analyzed to calculate scrambling coefficients. Instead, we recommend calculating $\gamma$ and $\kappa$ from reference materials that bracket the range of $\delta^{15} \mathrm{~N}^{\alpha}$ and $\delta^{15} \mathrm{~N}^{\beta}$ expected for the unknowns. We also recommend that a scale decompression, if applied, brackets the range of unknowns but excludes reference materials such as EMPA2 that lie far outside the expected ranges of $\delta^{15} \mathrm{~N}^{\alpha}$ and $\delta^{15} \mathrm{~N}^{\beta}$.

\subsection{MATLAB vs. Python}

To compare the performance of the Python and MATLAB versions of pyisotopomer, a week's worth of paired reference materials (atmosphere-equilibrated seawater, S2 reference gas, and B6 reference gas) from December 2020 was processed in both versions of the software. The resulting mean scrambling coefficients were used to re-calculate isotopocules for each reference material. The differences between MATLAB and Python results for $\gamma$ and $\kappa$ were both $\sim 0.001$, which represents a significant difference (see section 4.6). Using the MATLAB scrambling coefficients in the MATLAB isotopomers solver, and the Python scrambling coefficients in the Python isotopomers solver, the resulting $\delta^{15} \mathrm{~N}^{\alpha}, \delta^{15} \mathrm{~N}^{\beta}$, and $\delta^{18} \mathrm{O}_{\mathrm{N} 2 \mathrm{O}}$ (and thus site preference, $\delta^{15} \mathrm{~N}^{\text {bulk }}$ and $\delta^{17} \mathrm{O}_{\mathrm{N} 2 \mathrm{O}}$ ), showed extremely similar values (Table $\mathrm{S} 1$, Figure 2 ). Results from MATLAB and Python diverged in the second decimal place for $\delta^{15} \mathrm{~N}^{\alpha}$ and $\delta^{15} \mathrm{~N}^{\beta}$ (Table S1, Figure 2), and differences in the fourth decimal place for $\delta^{18} \mathrm{O}_{\mathrm{N} 2 \mathrm{O}}$ (not shown). The final output isotopocule values from MATLAB and Python had pooled standard deviations of $0.028 \%$, $0.026 \%$, and $0.054 \%$ for $\delta^{15} \mathrm{~N}^{\alpha}, \delta^{15} \mathrm{~N}^{\beta}$, and SP, respectively. Thus, we recommend that if the MATLAB version of pyisotopomer is used to calculate scrambling, the MATLAB version should also be used to calculate isotopocules, and likewise if the Python version of pyisotopomer is used to calculate scrambling, the Python version should also be used to calculate isotopocules.

\subsection{Variability in fragmentation behavior}

To examine the change in the fragmentation behavior of a single IRMS over time, the scrambling coefficients for the Lab 1 IRMS were compiled from 2018-2021 (Figure 3). A running average was calculated using a window size of 20, equivalent to 20 pairs of reference materials. High volatility in $\gamma$ and $\kappa$ in March-April 2019 (sample pair numbers 20-40) coincided with a period where the lab temperature was poorly controlled, and thus exhibited strong daynight variation. Before and after this period, the fragmentation behavior of the instrument exhibited smaller variations (Figure 3). The rolling standard deviation of $\gamma$ and $\kappa$ (not shown) confirms that the highest standard deviation of a 20-sample window occurred during April 2019, with the rolling standard deviation in $\gamma$ equal to 0.0018 , or a relative uncertainty of $1.03 \%$, and the rolling standard deviation in $\kappa$ equal to 0.0025 , or a relative uncertainty of $3.40 \%$. The standard deviation of $\gamma$ across the full dataset of scrambling over time was 0.0019 , and the standard deviation of $\kappa$ across the full dataset was 0.0018 .

There are several reasons why the scrambling behavior of the ion source might change over time. The $\mathrm{NO}^{+}$fragment ion can be produced by one of several routes from $\mathrm{N}_{2} \mathrm{O}^{+} .64,65$ The 
pathways and associated isotope effects for the formation of fragment ions are affected by collision frequency, the distribution of excited states, and the time spent in the ion source, which suggests that ion source conditions such as vapor pressure, ionizing energy, and accelerating voltage may all influence the fragmentation behavior of an IRMS system at a given time..$^{50,64-67}$ For these reasons, performing the scrambling calibration only once is not sufficient to obtain high-quality $\mathrm{N}_{2} \mathrm{O}$ isotopocule data. Instead, it is important to recalibrate an IRMS system for scrambling on a regular basis since ion source conditions may change with time and can shift abruptly with events such as filament changes. We recommend using a running average of $\gamma$ and $\kappa$ over a window of 20 sample pairs, equal to 5 runs of samples with four potential sample pairs per run, rather than calibrating based on day-to-day variation in $\gamma$ and $\kappa$. If there is high volatility in $\gamma$ and $\kappa$, as seen above in March-April 2019, it may be necessary to shorten this window, at the likely expense of accuracy in isotopocule measurements.

\subsection{Sensitivity of isotopomers to uncertainty in scrambling coefficients}

To quantify the effect of uncertainty in $\gamma$ and $\kappa$ on $\delta^{15} \mathrm{~N}^{\alpha}, \delta^{15} \mathrm{~N}^{\beta}$, and SP, a Monte Carlo simulation was used to introduce random uncertainty in the $\gamma$ and $\kappa$ values used to calculate these isotopomers from the measured isotope ratios of three reference materials run on December $7^{\text {th }}$, 2020. Based on past instrument performance (see section 4.5), we modeled $\gamma$ as a random number centered around $\gamma=0.1722$ with a standard deviation of 0.00192 , which is the cumulative standard deviation of all values of $\gamma$ for the Lab 1 IRMS from 2018-2021 and corresponds to a relative uncertainty of $1.11 \%$. Likewise, we modeled $\kappa$ as a random number centered around $\kappa=0.0797$ with a standard deviation of 0.00184 , which is the cumulative standard deviation of all values of $\kappa$ for the Lab 1 IRMS from 2018-2021 and corresponds to a relative uncertainty of $2.31 \%$. We sampled 1,000 pairs of $\gamma$ and $\kappa$ from normal distributions with these means and standard deviations, and then used these values of $\gamma$ and $\kappa$ to calculate the 1,000 simulated values of $\delta^{15} \mathrm{~N}^{\alpha}, \delta^{15} \mathrm{~N}^{\beta}$, and SP for the three measured reference materials ("S2", "B6", and atmosphereequilibrated seawater; Table 1). We determined the resulting uncertainties in each isotopomer by taking a pooled standard deviation across the three reference materials.

This analysis showed that a small relative uncertainty in each scrambling coefficient can lead to per mil-level errors in $\delta^{15} \mathrm{~N}^{\alpha}, \delta^{15} \mathrm{~N}^{\beta}$, and SP. Specifically, relative uncertainties of $1.11 \%$ and $2.31 \%$ in $\gamma$ and $\kappa$, respectively, resulted in pooled standard deviations of $3.61 \%$ in $\delta^{15} \mathrm{~N}^{\alpha}$ and $\delta^{15} \mathrm{~N}^{\beta}$ (the pooled standard deviations for $\delta^{15} \mathrm{~N}^{\alpha}$ and $\delta^{15} \mathrm{~N}^{\beta}$ were equivalent), and 7.23\%o in SP (Figure 4). Modeling $\gamma$ and $\kappa$ with relative uncertainties $0.39 \%$ and $0.16 \%$, instead, which were the uncertainties in each parameter based on reference materials run over two days (see section 4.3), led to pooled standard deviations of $0.98 \%$ in $\delta^{15} \mathrm{~N}^{\alpha}, \delta^{15} \mathrm{~N}^{\beta}$, and $1.95 \%$ in SP (Figure S2).

Performing this exercise along a range of modeled uncertainties in $\gamma$ and $\kappa$ produced a response curve of the expected standard deviations in each isotopomer for a given level of uncertainty in in $\gamma$ and $\kappa$ (Figure S3). Fitting a linear regression through each curve, we obtain equations of form $y=m x+b$ for SP and $\delta^{15} \mathrm{~N}^{\alpha}$ (the response curves for $\delta^{15} \mathrm{~N}^{\alpha}$ and $\delta^{15} \mathrm{~N}^{\beta}$ were identical). Solving for the uncertainty in $\gamma$ and $\kappa$ needed to achieve $1 \%$ pooled standard deviation for SP gives $\mathrm{x}=0.197 \%$. In other words, to obtain site preference values with an uncertainty of $1 \%$, the relative uncertainties in $\gamma$ and $\kappa$ should be reduced to less than $\sim 0.2 \%$. Averaging scrambling coefficients over a greater number of reference material pairings under the same ion source conditions should reduce their uncertainty; thus, we recommend calculating $\gamma$ and $\kappa$ from 
$\mathrm{a} \sim 1$-week moving average, instead of daily. Using a one-week moving average of each scrambling coefficient for the intercalibration exercise below (see section 4.7), we found relative uncertainties in $\gamma$ and $\kappa$ of $0.4 \%$ and $0.2 \%$, respectively - which are close to this target. We do not recommend calculating $\gamma$ and $\kappa$ from a cumulative average or cumulative moving average that includes longer term changes in ion source conditions, which can affect $\gamma$ and $\kappa$.

\subsection{Intercalibration}

The application of pyisotopomer was tested through an intercalibration including four reference materials and two Lake Lugano samples measured by two IRMS laboratories (Table 3). Pyisotopomer was used to perform the scrambling calibration for each laboratory and to obtain isotopocule ratios. Afterwards, a scale decompression was applied, as described in the Methods. The root mean square deviation (RMSD) for each reference material was calculated by comparison to the calibrated values provided by a previous intercalibration effort ${ }^{52}$ (atmosphereequilibrated seawater) and J. Mohn (EMPA1, EMPA2, and EMPA3).

The $\delta^{15} \mathrm{~N}^{\text {bulk }}$ measured by the two labs displayed good agreement for three out of the four reference materials, as well as the lake water samples. The $\delta^{15} \mathrm{~N}^{\text {bulk }}$ RMSDs for atmosphereequilibrated seawater and reference material EMPA3 were $0.71 \%$ and $0.50 \%$, respectively, both of which represent an improvement upon the intercalibration presented by Mohn et al. (2014). In contrast, the RMSD for EMPA1 was $2.46 \%$, larger than the $0.8 \%$ presented for IRMS labs by Mohn et al., 2014 (Table 3). The RMSD for EMPA2 was highest at 3.59\%, but this is to be expected, given that EMPA2 was excluded from the scrambling calculation and scale decompression conducted in this study due to its extreme values (see section 4.3). For the lake water sample taken at $10 \mathrm{~m}$ depth, the $\delta^{15} \mathrm{~N}^{\text {bulk }}$ values measured by Lab 1 and Lab 2 were statistically indistinguishable (Table 3; Figure S4). For the lake water sample taken at $90 \mathrm{~m}$ depth, the $\delta^{15} \mathrm{~N}^{\text {bulk }}$ values measured by Lab 1 and Lab 2 were $-5.00 \pm 0.08 \%$ and $-6.29 \pm 1.06 \%$, respectively (Table 3; Figure $\mathrm{S} 4$ ).

The $\delta^{15} \mathrm{~N}^{\alpha}$ measured by the two labs also showed good agreement for reference materials EMPA1, EMPA3, and atmosphere-equilibrated seawater: in each case, the combined RMSD was less than 2.60\% (Table 3). This is similar to the data presented in Mohn et al. (2014), who find an RMSD for $\delta^{15} \mathrm{~N}^{\alpha}$ for IRMS laboratories of $2.47 \%$. The values of $\delta^{15} \mathrm{~N}^{\alpha}$ measured by the two labs for the lake water unknowns differed by $\sim 2-3 \%$, but no consistent offset emerged between the two labs, and neither did such an offset emerge in the reference materials (i.e., the values for some samples were higher in Lab 1, and others are higher for Lab 2; Figure S4). For $\delta^{15} \mathrm{~N}^{\beta}$, the RMSD for atmosphere-equilibrated seawater, EMPA1, and EMPA3 were slightly larger, and only EMPA3 represents an improvement upon the data presented in previous intercalibrations (Table 3). The $\delta^{15} \mathrm{~N}^{\beta}$ measured by Lab 1 for the lake water unknowns was 1-2\%o different from that measured by Lab 2, but again, no consistent offset emerged (Figure S4).

The SP values measured by the two laboratories showed larger standard deviations than the $\delta^{15} \mathrm{~N}^{\alpha}$ and $\delta^{15} \mathrm{~N}^{\beta}$ individually, which is to be expected, since SP is a measure of difference between the latter two parameters. The RMSD values, however, were all less than $3 \%$ o for atmosphere-equilibrated seawater, EMPA1, and EMPA3 (Table 3). This represents an improvement on Mohn et al. (2014), who find an RMSD of 4.29\%o for SP measured by IRMS laboratories. The Lake Lugano unknowns showed larger offsets than the reference materials (Figure S4). The lake water sample from $10 \mathrm{~m}$ depth showed an especially large difference in SP between Lab 1 and Lab 2: Lab 1 measured a mean SP of 16.43 $\pm 1.35 \%$ at this depth, while Lab 2 
measured a mean SP of $20.77 \pm 2.67 \%$ (Table 3). At $90 \mathrm{~m}$ depth, Lab 1 measured a mean SP of $54.40 \pm 1.23 \%$, and Lab 2 measured a mean SP of $55.09 \pm 1.69 \%$.

For $\delta^{18} \mathrm{O}_{\mathrm{N} 2 \mathrm{O}}$, Lab 1 obtained consistently higher values than Lab 2, despite the application of a scale decompression, which should compensate for such offsets. ${ }^{52}$ The only exception to this rule was the lake water unknown from $10 \mathrm{~m}$ depth, for which the $\delta^{18} \mathrm{O}_{\mathrm{N} 2 \mathrm{O}}$ values measured by the two labs were statistically indistinguishable (Table 3; Figure S4). For the other samples and reference materials, the magnitude of this offset varied from $2.81 \%$ (EMPA3) to $6.80 \%$ (lake water unknown from $90 \mathrm{~m}$ ). For reference materials EMPA1 and EMPA3, the $\delta^{18} \mathrm{O}_{\mathrm{N} 2 \mathrm{O}}$ values measured by Lab 1 were $2-3 \%$ higher than the calibrated $\delta^{18} \mathrm{O}_{\mathrm{N} 2 \mathrm{O}}$ (Tables $1 \& 3$ ), while the $\delta^{18} \mathrm{O}_{\mathrm{N} 2 \mathrm{O}}$ values measured by Lab 2 did not exhibit such an offset. For atmosphere-equilibrated seawater, the $\delta^{18} \mathrm{O}_{\mathrm{N} 2 \mathrm{O}}$ values measured by Lab 2 were $\sim 3 \%$ lower than the calibrated $\delta^{18} \mathrm{O}_{\mathrm{N} 2 \mathrm{O}}$

598 (Tables $1 \& 3$ ), while the $\delta^{18} \mathrm{O}_{\mathrm{N} 2 \mathrm{O}}$ values measured by Lab 1 did not exhibit such an offset. This offset did not exhibit any dependence on $\mathrm{N}_{2} \mathrm{O}$ concentration - rather, the variation in $\delta^{18} \mathrm{O}_{\mathrm{N} 2 \mathrm{O}}$ values tended to be larger for lower peak areas, resulting in greater offsets, but without any measurable trend (cite figure or table?). Similarly, the linearity correction could not correct for

\section{Conclusion: How to obtain high-quality $\mathrm{N}_{2} \mathrm{O}$ isotopocule data using pyisotopomer}

Using pyisotopomer and at least two reference materials (three characterized gases, assuming the $\mathrm{N}_{2} \mathrm{O}$ reference tank is also calibrated), one can calculate scrambling for a given IRMS and apply those scrambling coefficients to calculate the isotopocule values of unknown samples. To ensure high-quality results from these calculations, we provide the following recommendations. Firstly, if scrambling has never been calculated for the IRMS or current filament, iterate through the scrambling calculation twice. Use the solution from the first iteration as the initial guess for subsequent calculations. This can be achieved with the "initialguess" argument to the Scrambling function of pyisotopomer. In a similar vein, use the default settings for the lower and upper bounds for both the Scrambling and Isotopomers solvers. These settings allow the solvers to search for solutions across the widest possible range of values. Secondly, to calculate scrambling, where possible, choose pairings of reference materials that bracket the range of unknowns but do not have $\delta^{15} \mathrm{~N}^{\alpha}, \delta^{15} \mathrm{~N}^{\beta}$, or $\delta^{18} \mathrm{O}_{\mathrm{N} 2 \mathrm{O}}$ that lie far outside of this range. The same is true for scale decompression. Third, if the MATLAB version of pyisotopomer is used to calculate scrambling, the MATLAB version should also be used to calculate isotopocules. Finally, it is necessary to run paired reference materials daily to obtain accurate running estimates of $\gamma$ and $\kappa$. It is recommended to calculate convert these daily estimates to a 1 -week running average and use that average to calculate isotopocules. For a $1 \%$ precision in SP, the standard deviation of this running average should represent no more than a $0.2 \%$ uncertainty in $\gamma$ and $\kappa$.

Using pyisotopomer in an intercalibration exercise and implementing the above recommendations, we find good agreement between the isotopocules measured by two different IRMS labs for both reference materials and natural lake samples. We conclude that while the intercalibration results demonstrate potential for further improvement in both precision and accuracy, the intercalibration of SP using a uniform scrambling calculation (pyisotopomer) presented here represents an improvement upon previous $\mathrm{N}_{2} \mathrm{O}$ intercalibrations. 


\section{Data availability statement}

633 The manuscript is prepared to comply with the RCMS data policy. The latest version of

634 pyisotopomer is available for installation via the Python Package index

635 (pypi.org/project/pyisotopomer). The first release of pyisotopomer is also available via Zenodo

636 for both Python (doi.org/10.5281/zenodo.5031218) and MATLAB

637 (doi.org/10.5281/zenodo.5031237). This research was supported by U.S.-NSF grant OCE-

6381657868 to K. L. Casciotti. C. L. Kelly is supported by an NSF Graduate Research Fellowship.

639 The authors declare no competing financial interests. 


\section{References}

1. Yung YL, Wang WC, Lacis AA. Greenhouse effect due to atmospheric nitrous oxide. Geophys Res Lett. 1976;3(10):619-621. doi:10.1029/GL003i010p00619

2. Smith C, Nicholls ZRJ, Armour K, et al. The Earth's Energy Budget, Climate Feedbacks, and Climate Sensitivity Supplementary Material. In: Masson-Delmotte V, Zhai P, Pirani A, et al., eds. Climate Change 2021: The Physical Science Basis. Contribution of Working Group I to the Sixth Assessment Report of the Intergovernmental Panel on Climate Change. Cambridge University Press; 2021. Accessed October 4, 2021. https://www.ipcc.ch/report/ar6/wg1/downloads/report/IPCC_AR6_WGI_Chapter_07_Supp lementary_Material.pdf

3. Crutzen PJ. The influence of nitrogen oxides on the atmospheric ozone content. $Q J R$ Meteorol Soc. 1970;96(408):320-325. doi:10.1002/qj.49709640815

4. Ravishankara AR, Daniel JS, Portmann RW. Nitrous Oxide (N2O): The Dominant OzoneDepleting Substance Emitted in the 21st Century. Science. 2009;326(5949):123-125. doi:10.1126/science. 1176985

5. Wuebbles DJ. Nitrous Oxide: No Laughing Matter. Science. 2009;326(5949):56-57. doi:10.1126/science.1179571

6. Müller R. The impact of the rise in atmospheric nitrous oxide on stratospheric ozone. Ambio. 2021;50(1):35-39. doi:10.1007/s13280-020-01428-3

7. Kim KR, Craig H. Nitrogen-15 and Oxygen-18 Characteristics of Nitrous Oxide: A Global Perspective. Science. 1993;262(5141):1855-1857. doi:10.1126/science.262.5141.1855

8. Pérez T, Trumbore SE, Tyler SC, Davidson EA, Keller M, Camargo PB de. Isotopic variability of $\mathrm{N} 2 \mathrm{O}$ emissions from tropical forest soils. Glob Biogeochem Cycles. 2000;14(2):525-535. doi:10.1029/1999GB001181

9. Rahn T, Wahlen M. Stable Isotope Enrichment in Stratospheric Nitrous Oxide. Science. 1997;278(5344):1776-1778. doi:10.1126/science.278.5344.1776

10. Rahn T, Wahlen M. A reassessment of the global isotopic budget of atmospheric nitrous oxide. Glob Biogeochem Cycles. 2000;14(2):537-543. doi:10.1029/1999GB900070

11. Kim KR, Craig H. Two-isotope characterization of N20 in the Pacific Ocean and constraints on its origin in deep water. Nature. 1990;347(6288):58-61. doi: $10.1038 / 347058 \mathrm{a} 0$

12. Dore JE, Popp BN, Karl DM, Sansone FJ. A large source of atmospheric nitrous oxide from subtropical North Pacific surface waters. Nature. 1998;396(6706):63-66. doi: $10.1038 / 23921$ 
13. Naqvi SWA, Naik H, Jayakumar A, et al. Seasonal anoxia Over the Western Indian Continental Shelf. In: Wiggert JD, Hood RR, Naqvi SWA, Brink KH, Smith SL, eds. Geophysical Monograph Series. Vol 185. American Geophysical Union; 2009:333-345. doi:10.1029/2008GM000745

14. Yoshida N, Hattori A, Saino T, Matsuo S, Wada E. $15 \mathrm{~N} / 14 \mathrm{~N}$ ratio of dissolved N2O in the eastern tropical Pacific Ocean. Nature. Published online 1984. doi:10.1038/307442A0

15. Yoshida N. 15N-depleted N2O as a product of nitrification. Nature. 1988;335(6190):528529. doi:10.1038/335528a0

16. Barford CC, Montoya JP, Altabet MA, Mitchell R. Steady-State Nitrogen Isotope Effects of N2 and N2O Production in Paracoccus denitrificans. Appl Environ Microbiol. 1999;65(3):989-994. doi:10.1128/AEM.65.3.989-994.1999

17. Friedman L, Bigeleisen J. Oxygen and Nitrogen Isotope Effects in the Decomposition of Ammonium Nitrate. J Chem Phys. 1950;18(10):1325-1331. doi:10.1063/1.1747471

18. Toyoda S, Yoshida N. Determination of nitrogen isotopomers of nitrous oxide on a modified isotope ratio mass spectrometer. Anal Chem. 1999;71(20):4711-4718. doi:10.1021/ac9904563

19. Brenninkmeijer C a. M, Röckmann T. Mass spectrometry of the intramolecular nitrogen isotope distribution of environmental nitrous oxide using fragment-ion analysis. Rapid Commun Mass Spectrom. 1999;13(20):2028-2033. doi:10.1002/(SICI)10970231(19991030)13:20<2028::AID-RCM751>3.0.CO;2-J

20. Röckmann T, Levin I. High-precision determination of the changing isotopic composition of atmospheric N2O from 1990 to 2002. J Geophys Res Atmospheres. 2005;110(D21). doi:10.1029/2005JD006066

21. Yung YL, Miller CE. Isotopic Fractionation of Stratospheric Nitrous Oxide. Science. 1997;278(5344):1778-1780. doi:10.1126/science.278.5344.1778

22. Yoshida null, Toyoda null. Constraining the atmospheric $\mathrm{N} 2 \mathrm{O}$ budget from intramolecular site preference in N2O isotopomers. Nature. 2000;405(6784):330-334. doi: $10.1038 / 35012558$

23. Röckmann T, Kaiser J, Brenninkmeijer CAM, et al. Isotopic enrichment of nitrous oxide $(15 \mathrm{~N} 14 \mathrm{NO}, 14 \mathrm{~N} 15 \mathrm{NO}, 14 \mathrm{~N} 14 \mathrm{~N} 18 \mathrm{O})$ in the stratosphere and in the laboratory. $J$ Geophys Res Atmospheres. 2001;106(D10):10403-10410. doi:10.1029/2000JD900822

24. Toyoda S, Yoshida N, Urabe T, et al. Temporal and latitudinal distributions of stratospheric N2O isotopomers. J Geophys Res Atmospheres. 2004;109(D8). doi:10.1029/2003JD004316

25. Kaiser J, Engel A, Borchers R, Rockmann T. Probing stratospheric transport and chemistry with new balloon and aircraft observations of the meridional and vertical N2O isotope distribution. Atmos Chem Phys. Published online 2006:22. 
26. Park S, Atlas EL, Boering KA. Measurements of N2O isotopologues in the stratosphere: Influence of transport on the apparent enrichment factors and the isotopologue fluxes to the troposphere. J Geophys Res Atmospheres. 2004;109(D1). doi:10.1029/2003JD003731

27. Toyoda S, Yoshida N, Miwa T, et al. Production mechanism and global budget of N2O inferred from its isotopomers in the western North Pacific. Geophys Res Lett. 2002;29(3):71-7-4. doi:10.1029/2001GL014311

28. Sutka RL, Ostrom NE, Ostrom PH, Gandhi H, Breznak JA. Nitrogen isotopomer site preference of $\mathrm{N} 2 \mathrm{O}$ produced by Nitrosomonas europaea and Methylococcus capsulatus Bath. Rapid Commun Mass Spectrom RCM. 2003;17(7):738-745. doi:10.1002/rcm.968

29. Sutka RL, Ostrom NE, Ostrom PH, et al. Distinguishing Nitrous Oxide Production from Nitrification and Denitrification on the Basis of Isotopomer Abundances. Appl Environ Microbiol. 2006;72(1):638-644. doi:10.1128/AEM.72.1.638-644.2006

30. Sutka RL, Ostrom NE, Ostrom PH, Gandhi H, Breznak JA. Nitrogen isotopomer site preference of $\mathrm{N} 2 \mathrm{O}$ produced by Nitrosomonas europaea and Methylococcus capsulatus Bath. Rapid Commun Mass Spectrom. 2004;18(12):1411-1412. doi:10.1002/rcm.1482

31. Toyoda S, Mutobe H, Yamagishi H, Yoshida N, Tanji Y. Fractionation of N2O isotopomers during production by denitrifier. Soil Biol Biochem. 2005;37(8):1535-1545. doi:10.1016/j.soilbio.2005.01.009

32. Frame $\mathrm{CH}$, Casciotti KL. Biogeochemical controls and isotopic signatures of nitrous oxide production by a marine ammonia-oxidizing bacterium. Biogeosciences. 2010;7(9):26952709. doi:https://doi.org/10.5194/bg-7-2695-2010

33. Schmidt HL, Werner RA, Yoshida N, Well R. Is the isotopic composition of nitrous oxide an indicator for its origin from nitrification or denitrification? A theoretical approach from referred data and microbiological and enzyme kinetic aspects. Rapid Commun Mass Spectrom. 2004;18(18):2036-2040. doi:10.1002/rcm.1586

34. Ostrom NE, Pitt A, Sutka R, et al. Isotopologue effects during N2O reduction in soils and in pure cultures of denitrifiers. J Geophys Res Biogeosciences. 2007;112(G2). doi:10.1029/2006JG000287

35. Lewicka-Szczebak D, Augustin J, Giesemann A, Well R. Quantifying N2O reduction to N2 based on $\mathrm{N} 2 \mathrm{O}$ isotopocules - validation with independent methods (helium incubation and $15 \mathrm{~N}$ gas flux method). Biogeosciences. 2017;14(3):711-732. doi:https://doi.org/10.5194/bg14-711-2017

36. Casciotti KL, Forbes M, Vedamati J, Peters BD, Martin TS, Mordy CW. Nitrous oxide cycling in the Eastern Tropical South Pacific as inferred from isotopic and isotopomeric data. Deep Sea Res Part II Top Stud Oceanogr. 2018;156:155-167. doi:10.1016/j.dsr2.2018.07.014 
37. Kelly CL, Travis NM, Baya PA, Casciotti KL. Quantifying Nitrous Oxide Cycling Regimes in the Eastern Tropical North Pacific Ocean With Isotopomer Analysis. Glob Biogeochem Cycles. 2021;35(2):e2020GB006637. doi:https://doi.org/10.1029/2020GB006637

38. Pérez T, Trumbore SE, Tyler SC, et al. Identifying the agricultural imprint on the global N2O budget using stable isotopes. $J$ Geophys Res Atmospheres. 2001;106(D9):9869-9878. doi:10.1029/2000JD900809

39. Yamulki S, Toyoda S, Yoshida N, Veldkamp E, Grant B, Bol R. Diurnal fluxes and the isotopomer ratios of $\mathrm{N} 2 \mathrm{O}$ in a temperate grassland following urine amendment. Rapid Commun Mass Spectrom. 2001;15(15):1263-1269. doi:10.1002/rcm.352

40. Verhoeven E, Barthel M, Yu L, et al. Early season $\mathrm{N}_{2} \mathrm{O}$ emissions under variable water management in rice systems: source-partitioning emissions using isotope ratios along a depth profile. Biogeosciences. 2019;16(2):383-408. doi:https://doi.org/10.5194/bg-16-3832019

41. Popp BN, Westley MB, Toyoda S, et al. Nitrogen and oxygen isotopomeric constraints on the origins and sea-to-air flux of $\mathrm{N} 2 \mathrm{O}$ in the oligotrophic subtropical North Pacific gyre. Glob Biogeochem Cycles. 2002;16(4):12-1-12-10. doi:10.1029/2001GB001806

42. Yamagishi H, Westley MB, Popp BN, et al. Role of nitrification and denitrification on the nitrous oxide cycle in the eastern tropical North Pacific and Gulf of California. $J$ Geophys Res Biogeosciences. 2007;112(G2). doi:10.1029/2006JG000227

43. Yamagishi H, Yoshida N, Toyoda S, Popp BN, Westley MB, Watanabe S. Contributions of denitrification and mixing on the distribution of nitrous oxide in the North Pacific. Geophys Res Lett. 2005;32(4). doi:10.1029/2004GL021458

44. Westley MB, Yamagishi H, Popp BN, Yoshida N. Nitrous oxide cycling in the Black Sea inferred from stable isotope and isotopomer distributions. Deep Sea Res Part II Top Stud Oceanogr. 2006;53(17-19):1802-1816. doi:10.1016/j.dsr2.2006.03.012

45. Farías L, Castro-González M, Cornejo M, et al. Denitrification and nitrous oxide cycling within the upper oxycline of the eastern tropical South Pacific oxygen minimum zone. Limnol Oceanogr. 2009;54(1):132-144. doi:10.4319/1o.2009.54.1.0132

46. Bourbonnais A, Letscher RT, Bange HW, et al. N2O production and consumption from stable isotopic and concentration data in the Peruvian coastal upwelling system. Glob Biogeochem Cycles. 2017;31(4):678-698. doi:10.1002/2016GB005567

47. Toyoda S, Yoshida O, Yamagishi H, Fujii A, Yoshida N, Watanabe S. Identifying the origin of nitrous oxide dissolved in deep ocean by concentration and isotopocule analyses. Sci Rep. 2019;9(1):1-9. doi:10.1038/s41598-019-44224-0

48. Toyoda S, Kakimoto T, Kudo K, et al. Distribution and Production Mechanisms of N2O in the Western Arctic Ocean. Glob Biogeochem Cycles. 2021;35(4):e2020GB006881. doi:https://doi.org/10.1029/2020GB006881 
805

49. Kaiser J, Park S, Boering KA, Brenninkmeijer CAM, Hilkert A, Röckmann T. Mass spectrometric method for the absolute calibration of the intramolecular nitrogen isotope distribution in nitrous oxide. Anal Bioanal Chem. 2004;378(2):256-269. doi:10.1007/s00216-003-2233-2

50. Westley MB, Popp BN, Rust TM. The calibration of the intramolecular nitrogen isotope distribution in nitrous oxide measured by isotope ratio mass spectrometry. Rapid Commun Mass Spectrom. 2007;21(3):391-405. doi:10.1002/rcm.2828

51. Ostrom NE, Gandhi H, Coplen TB, et al. Preliminary assessment of stable nitrogen and oxygen isotopic composition of USGS51 and USGS52 nitrous oxide reference gases and perspectives on calibration needs. Rapid Commun Mass Spectrom. 2018;32(15):1207-1214. doi: $10.1002 / \mathrm{rcm} .8157$

52. Mohn J, Wolf B, Toyoda S, et al. Interlaboratory assessment of nitrous oxide isotopomer analysis by isotope ratio mass spectrometry and laser spectroscopy: current status and perspectives. Rapid Commun Mass Spectrom. 2014;28(18):1995-2007. doi:10.1002/rcm.6982

53. Kaiser J, Röckmann T, Brenninkmeijer CAM. Complete and accurate mass spectrometric isotope analysis of tropospheric nitrous oxide. J Geophys Res Atmospheres. 2003;108(D15). doi:10.1029/2003JD003613

54. Wankel SD, Ziebis W, Buchwald C, et al. Evidence for fungal and chemodenitrification based N 2 O flux from nitrogen impacted coastal sediments. Nat Commun. 2017;8(1):1-11. doi:10.1038/ncomms 15595

55. Baertschi P. Absolute 180 content of standard mean ocean water. Earth Planet Sci Lett. 1976;31(3):341-344. doi:10.1016/0012-821X(76)90115-1

56. Jabeen I, Kusakabe M. Determination of $\delta 17 \mathrm{O}$ values of reference water samples VSMOW and SLAP. Chem Geol. 1997;143:115-119. doi:10.1016/S0009-2541(97)00109-5

57. Magyar PM, Orphan VJ, Eiler JM. Measurement of rare isotopologues of nitrous oxide by high-resolution multi-collector mass spectrometry. Rapid Commun Mass Spectrom. 2016;30(17):1923-1940. doi:10.1002/rcm.7671

58. Kelly CL. Ckelly314/Pyisotopomer: Version 0.0.1. Zenodo; 2021. doi:10.5281/zenodo.5031218

59. McIlvin MR, Casciotti KL. Technical updates to the bacterial method for nitrate isotopic analyses. Anal Chem. 2011;83(5):1850-1856. doi:10.1021/ac1028984

60. McIlvin MR, Casciotti KL. Fully automated system for stable isotopic analyses of dissolved nitrous oxide at natural abundance levels. Limnol Oceanogr Methods. 2010;8(2):54-66. doi:10.4319/lom.2010.8.54 
61. Dutton GS, Elkins JW, Hall BD. Nitrous Oxide data from the NOAA/ESRL halocarbons in situ program. Published online 2021. Accessed November 19, 2021. https://data.nodc.noaa.gov/cgi-bin/iso?id=gov.noaa.ncdc:C01556

62. Santoro AE, Buchwald C, McIlvin MR, Casciotti KL. Isotopic Signature of N2O Produced by Marine Ammonia-Oxidizing Archaea. Science. 2011;333(6047):1282-1285. doi:10.1126/science. 1208239

63. Cohen J. Statistical Power Analysis for the Behavioral Sciences. Academic Press; 2013.

64. Lorquet JC, Cadet C. Excited states of gaseous ions: I. Selection rules in photoelectron spectroscopy and photoionization. The case of N2O+. Int J Mass Spectrom Ion Phys. 1971;7(3):245-254. doi:10.1016/0020-7381(71)80020-7

65. Märk E, Märk TD, Kim YB, Stephan K. Absolute electron impact ionization cross section from threshold up to $180 \mathrm{eV}$ for $\mathrm{N} 2 \mathrm{O}+\mathrm{e} \rightarrow \mathrm{N} 2 \mathrm{O}++2 \mathrm{e}$ and the metastable and collision induced dissociation of N2O+. J Chem Phys. 1981;75(9):4446-4453. doi:10.1063/1.442611

66. Bigeleis J. Isotope chemistry has opened new areas of chemic,al physics, geochemistry, and molecular biologry. Published online 1965:10.

67. Begun GM, Landau L. Metastable Transitions in N2O+. J Chem Phys. 1962;36(4):10831084. doi:10.1063/1.1732641 
838 Table 1: Reference materials for $\mathrm{N}_{2} \mathrm{O}$ isotopic analysis and intercalibration. The laboratories 839 participating in the intercalibration exercise were at Stanford University ("Lab 1") and the 840 University of Basel ('Lab 2").

841

\begin{tabular}{|c|c|c|c|c|c|c|}
\hline Reference material & $\delta^{15} \mathrm{~N}^{\alpha}$ & $\delta^{15} \mathrm{~N}^{\beta}$ & SP & $\delta^{15} \mathrm{~N}^{\text {bulk }}$ & $\delta^{18} \mathrm{O}_{\mathrm{N} 2 \mathrm{O}}$ & Calibration by \\
\hline & \multicolumn{4}{|c|}{$\left(\% \circ v\right.$ s. air $\left.\mathrm{N}_{2}\right)$} & (\%ovs. VSMOW) & \\
\hline $\mathrm{S} 2$ reference gas & 5.55 & -12.87 & 18.42 & -3.66 & 32.73 & S. Toyoda, Tokyo Tech \\
\hline B6 reference gas & -0.40 & -0.15 & -0.26 & -0.28 & 41.95 & Lab 1 internal standard \\
\hline $\begin{array}{l}\text { Atmosphere- } \\
\text { equilibrated seawater }\end{array}$ & 15.70 & -3.30 & 19.00 & 6.20 & 44.30 & Mohn et al. (2014) \\
\hline $\begin{array}{l}\text { EMPA1 reference gas } \\
\text { (CA06261) }\end{array}$ & -22.21 & -49.28 & 27.07 & -35.75 & 26.94 & J. Mohn, EMPA \\
\hline $\begin{array}{l}\text { EMPA2 reference gas } \\
\text { (CA08214) }\end{array}$ & 1.71 & 94.44 & -92.73 & 48.08 & 36.01 & J. Mohn, EMPA \\
\hline \multirow[t]{2}{*}{$\begin{array}{l}\text { EMPA3 reference gas } \\
(53504)\end{array}$} & 17.11 & -3.43 & 20.54 & 6.84 & 35.39 & J. Mohn, EMPA \\
\hline & ${ }^{31} \mathrm{R}$ & ${ }^{45} \mathrm{R}$ & ${ }^{46} \mathrm{R}$ & & & \\
\hline $\begin{array}{l}\mathrm{Lab} 1 \text { pure } \mathrm{N}_{2} \mathrm{O} \text { direct } \\
\text { injection }\end{array}$ & 0.003733763 & 0.007741025 & 0.002101295 & & & S. Toyoda, Tokyo Tech \\
\hline $\begin{array}{l}\mathrm{Lab} 2 \text { pure } \mathrm{N}_{2} \mathrm{O} \text { direct } \\
\text { injection }\end{array}$ & 0.004049069 & 0.007738762 & 0.002100262 & & & J. Mohn, EMPA \\
\hline
\end{tabular}


845 Table 2: Performance tests of pyisotopomer. A) The initial guess $\mathrm{x} 0$ used to solve for $\gamma$ and $\kappa$ was varied from $\gamma=\kappa=0.05$ to $\gamma=\kappa=0.20$. B) The lower bounds used to solve for $\gamma$ and $\kappa$ were varied from $\gamma=\kappa=0.0$ to $\gamma=\kappa=0.08$. C) The upper bounds used to solve for $\gamma$ and $\kappa$ was varied

848 from $\gamma=\kappa=0.4$ to $\gamma=\kappa=1.0$. D) The $\gamma$ and $\kappa$ used to calculated ${ }^{31} \mathrm{R}$ for the direct reference injection 849 were varied. For each test, the resulting range of solutions for $\gamma$ and $\kappa$ were used to calculate 850 isotopocule values for test reference materials. Reported values are the means and standard 851 deviations of the range of 50 solutions.

852

\begin{tabular}{|c|c|c|c|c|c|}
\hline \multirow[t]{2}{*}{ Sample ID } & $\delta^{15} \mathrm{~N}^{\alpha}$ & $\delta^{15} \mathrm{~N}^{\beta}$ & SP & $\delta^{15} \mathrm{~N}^{\text {bulk }}$ & \multirow{2}{*}{$\begin{array}{c}\delta^{18} \mathrm{O}_{\mathrm{N} 2 \mathrm{O}} \\
(\% \text { vs. VSMOW })\end{array}$} \\
\hline & \multicolumn{4}{|c|}{$\left(\% o v s\right.$. air $\left.N_{2}\right)$} & \\
\hline \multicolumn{6}{|l|}{ A. Varying initial guess $x 0$} \\
\hline Atmosphere-equilibrated seawater \#1 & $15.45 \pm 0.02$ & $-3.59 \pm 0.02$ & $19.03 \pm 0.03$ & $5.93 \pm 0.00$ & $45.39 \pm 0.00$ \\
\hline Atmosphere-equilibrated seawater \#2 & $14.85 \pm 0.04$ & $-3.22 \pm 0.04$ & $18.07 \pm 0.08$ & $5.82 \pm 0.00$ & $46.45 \pm 0.00$ \\
\hline S2 reference gas \#1 & $5.18 \pm 0.07$ & $-12.28 \pm 0.07$ & $17.46 \pm 0.13$ & $-3.55 \pm 0.00$ & $33.30 \pm 0.00$ \\
\hline $\mathrm{S} 2$ reference gas \#2 & $5.19 \pm 0.05$ & $-12.52 \pm 0.05$ & $17.71 \pm 0.10$ & $-3.66 \pm 0.00$ & $34.31 \pm 0.00$ \\
\hline \multicolumn{6}{|l|}{ B. Varying lower bounds } \\
\hline Atmosphere-equilibrated seawater \#1 & $15.51 \pm 0.00$ & $-3.66 \pm 0.00$ & $19.17 \pm 0.00$ & $5.93 \pm 0.00$ & $45.39 \pm 0.00$ \\
\hline Atmosphere-equilibrated seawater \#2 & $14.97 \pm 0.00$ & $-3.34 \pm 0.00$ & $18.30 \pm 0.00$ & $5.82 \pm 0.00$ & $46.45 \pm 0.00$ \\
\hline $\mathrm{S} 2$ reference gas \#1 & $5.32 \pm 0.00$ & $-12.42 \pm 0.00$ & $17.74 \pm 0.00$ & $-3.55 \pm 0.00$ & $33.30 \pm 0.00$ \\
\hline $\mathrm{S} 2$ reference gas \#2 & $5.32 \pm 0.00$ & $-12.64 \pm 0.00$ & $17.96 \pm 0.00$ & $-3.66 \pm 0.00$ & $34.31 \pm 0.00$ \\
\hline \multicolumn{6}{|l|}{ C. Varying upper bounds } \\
\hline Atmosphere-equilibrated seawater \#1 & $15.51 \pm 0.00$ & $-3.65 \pm 0.00$ & $19.16 \pm 0.01$ & $5.93 \pm 0.00$ & $45.39 \pm 0.00$ \\
\hline Atmosphere-equilibrated seawater \#2 & $14.97 \pm 0.00$ & $-3.33 \pm 0.00$ & $18.30 \pm 0.00$ & $5.82 \pm 0.00$ & $46.45 \pm 0.00$ \\
\hline S2 reference gas \#1 & $5.31 \pm 0.00$ & $-12.42 \pm 0.00$ & $17.73 \pm 0.00$ & $-3.55 \pm 0.00$ & $33.30 \pm 0.00$ \\
\hline S2 reference gas \#2 & $5.32 \pm 0.00$ & $-12.64 \pm 0.00$ & $17.96 \pm 0.00$ & $-3.66 \pm 0.00$ & $34.31 \pm 0.00$ \\
\hline \multicolumn{6}{|l|}{ D. Varying ref. injection scrambling } \\
\hline Atmosphere-equilibrated seawater \#1 & $15.40 \pm 0.13$ & $-3.54 \pm 0.13$ & $18.94 \pm 0.27$ & $5.93 \pm 0.00$ & $45.39 \pm 0.00$ \\
\hline $\mathrm{S} 2$ reference gas \#1 & $5.20 \pm 0.13$ & $-12.30 \pm 0.13$ & $17.50 \pm 0.27$ & $-3.55 \pm 0.00$ & $33.30 \pm 0.00$ \\
\hline
\end{tabular}


Table 3: $\mathrm{N}_{2} \mathrm{O}$ isotopic composition of four reference materials and two unknowns analyzed by two IRMS laboratories. $\delta^{15} \mathrm{~N}^{\alpha}, \delta^{15} \mathrm{~N}^{\beta}, \mathrm{SP}$, and $\delta^{15} \mathrm{~N}^{\text {bulk }}$ are reported in \%o vs. Air $\mathrm{N}_{2}$, and $\delta^{18} \mathrm{O}_{\mathrm{N} 2 \mathrm{O}}$ is reported in \%o vs. VSMOW. Uncertainties are standard deviations of replicate bottles and do not include the propagation of calibration uncertainties. The root-mean square deviation (RMSD) was calculated with respect to the calibration data presented in Table 1.

861

\begin{tabular}{|c|c|c|c|c|c|c|}
\hline Reference gas & & $\delta^{15} \mathrm{~N}^{\alpha}$ & $\delta^{15} \mathrm{~N}^{\beta}$ & SP & $\delta^{15} \mathrm{~N}^{\text {bulk }}$ & $\delta^{18} \mathrm{O}_{\mathrm{N} 2 \mathrm{O}}$ \\
\hline & & \multicolumn{4}{|c|}{$\left(\%\right.$ vs. air $\left.N_{2}\right)$} & (\%ovs. VSMOW) \\
\hline \multirow[t]{3}{*}{ Atmosphere-equilibrated seawater } & mean (Lab 1) & $15.46 \pm 0.72$ & $-3.12 \pm 2.00$ & $18.58 \pm 2.43$ & $6.17 \pm 0.89$ & $44.67 \pm 2.08$ \\
\hline & mean (Lab 2) & $16.88 \pm 1.82$ & $-4.21 \pm 1.75$ & $21.09 \pm 3.51$ & $6.34 \pm 0.33$ & $40.81 \pm 1.04$ \\
\hline & RMSD (Labs $1 \&$ 2) & 1.20 & 1.81 & 2.73 & 0.71 & 6.49 \\
\hline \multirow[t]{3}{*}{ EMPA1 } & mean (Lab 1) & $-17.77 \pm 1.69$ & $-43.88 \pm 1.89$ & $26.12 \pm 3.55$ & $-30.83 \pm 0.23$ & $30.31 \pm 1.27$ \\
\hline & mean (Lab 2) & $-22.41 \pm 1.55$ & $-49.19 \pm 2.42$ & $26.78 \pm 3.71$ & $-35.80 \pm 0.83$ & $27.01 \pm 1.68$ \\
\hline & RMSD (Labs 1 \& 2) & 2.57 & 3.10 & 2.89 & 2.46 & 2.04 \\
\hline \multirow[t]{3}{*}{ EMPA2* } & mean (Lab 1) & $2.49 \pm 1.33$ & $82.89 \pm 1.69$ & $-80.40 \pm 2.39$ & $42.69 \pm 0.94$ & $39.36 \pm 0.79$ \\
\hline & mean (Lab 2) & $-10.43 \pm 1.44$ & $102.16 \pm 3.86$ & $-112.60 \pm 4.46$ & $45.87 \pm 1.88$ & $35.44 \pm 1.35$ \\
\hline & RMSD (Labs $1 \&$ 2) & 10.96 & 9.82 & 19.53 & 3.59 & 2.07 \\
\hline \multirow[t]{3}{*}{ EMPA3 } & mean (Lab 1) & $16.55 \pm 1.75$ & $-2.90 \pm 0.95$ & $19.99 \pm 2.49$ & $7.10 \pm 0.66$ & $37.85 \pm 1.25$ \\
\hline & mean (Lab 2) & $17.11 \pm 1.31$ & $-3.51 \pm 1.30$ & $20.62 \pm 2.28$ & $6.80 \pm 0.64$ & $35.04 \pm 3.34$ \\
\hline & RMSD (Labs 1 \& 2) & 1.31 & 1.04 & 2.13 & 0.50 & 2.32 \\
\hline \multirow[t]{2}{*}{ Unknown \#1 (Lake Lugano, 10m depth) } & mean (Lab 1) & $11.93 \pm 0.29$ & $-4.51 \pm 1.05$ & $16.43 \pm 1.35$ & $3.71 \pm 0.38$ & $44.56 \pm 1.16$ \\
\hline & mean (Lab 2) & $14.49 \pm 1.34$ & $-6.28 \pm 1.47$ & $20.77 \pm 2.67$ & $4.10 \pm 0.44$ & $44.90 \pm 1.64$ \\
\hline \multirow[t]{2}{*}{ Unknown \#2 (Lake Lugano, 90m depth) } & mean (Lab 1) & $22.20 \pm 0.55$ & $-32.20 \pm 0.68$ & $54.40 \pm 1.23$ & $-5.00 \pm 0.08$ & $60.68 \pm 0.04$ \\
\hline & mean (Lab 2) & $21.26 \pm 1.91$ & $-33.81 \pm 0.22$ & $55.09 \pm 1.69$ & $-6.26 \pm 1.06$ & $53.88 \pm 4.69$ \\
\hline *Large errors are due to exclusion from s & crambling calibr & & & & & \\
\hline
\end{tabular}

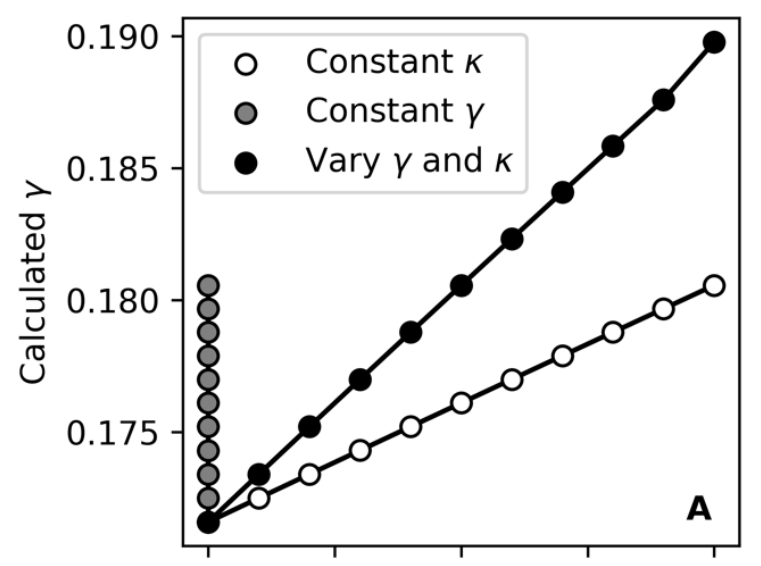

0.17000 .17250 .17500 .17750 .1800 Ref. injection $\gamma$

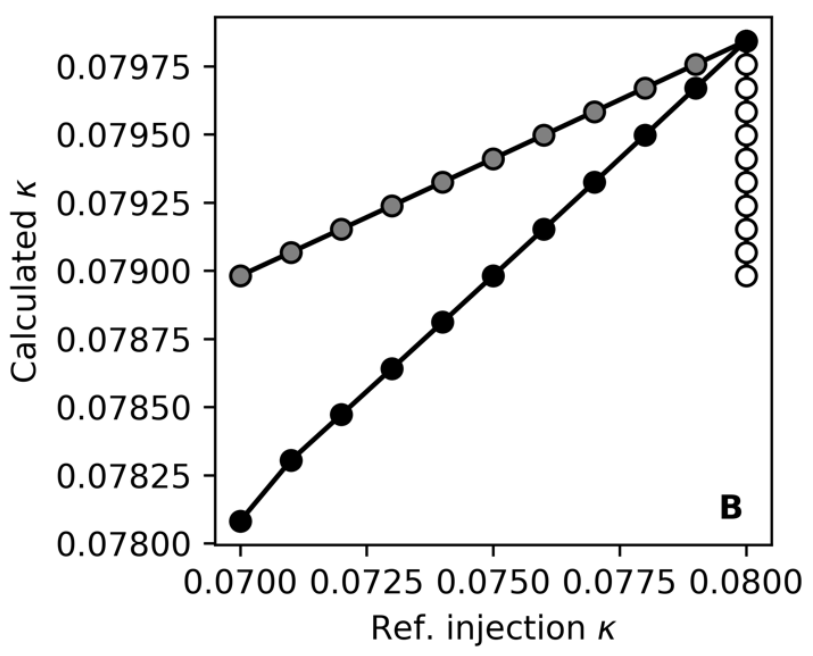

864

865 Figure 1. Solutions for $\gamma(\mathrm{A})$ and $\kappa(\mathrm{B})$ calculated across a range of theoretical $\gamma$ and $\kappa$ for the 866 867 direct reference injection: changing the reference injection $\gamma$ and holding the reference injection $\kappa$ constant (white), changing the reference injection $\kappa$ and holding the reference injection $\gamma$ constant (gray), changing both reference injection $\gamma$ and $\kappa$ (black). 


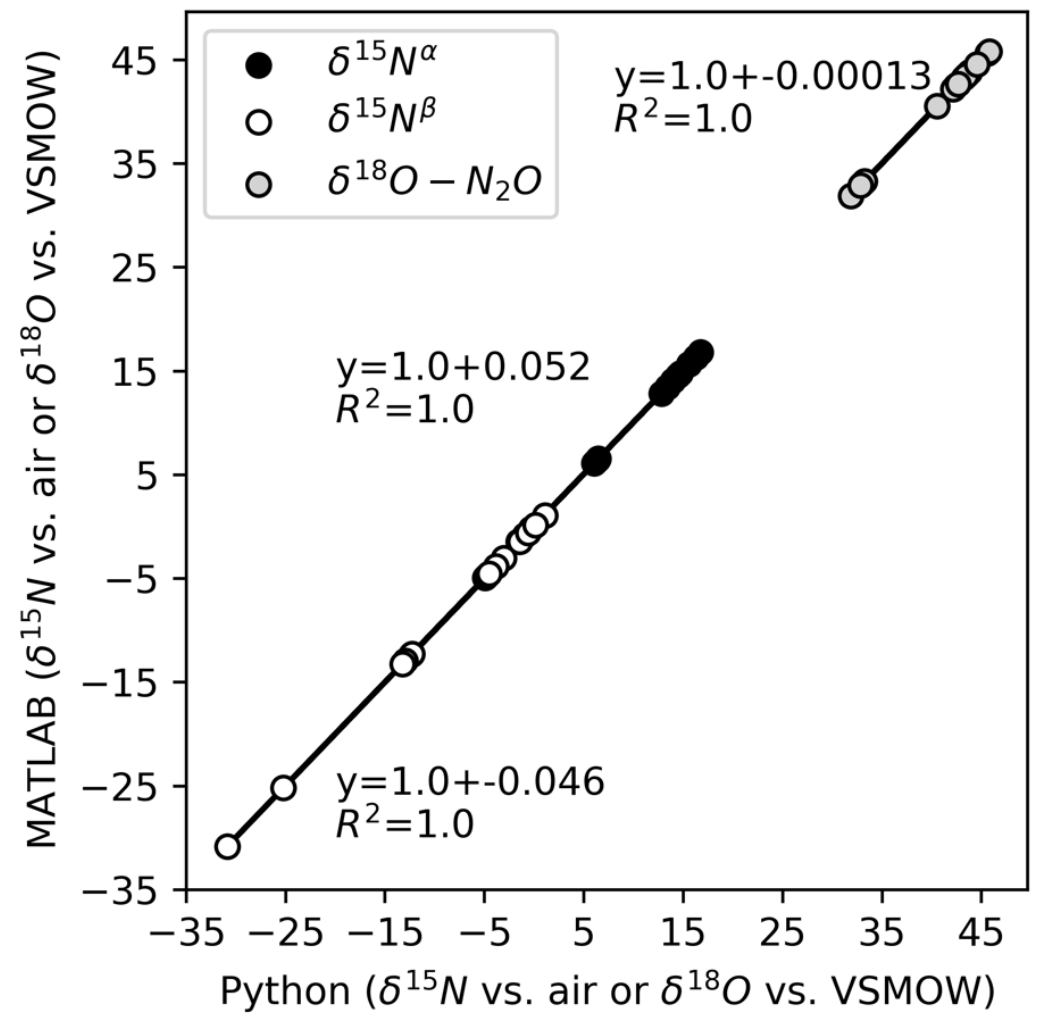

869

870 Figure 2. Comparison of isotopocule results for Python and MATLAB versions of 871 pyisotopomer.

872 


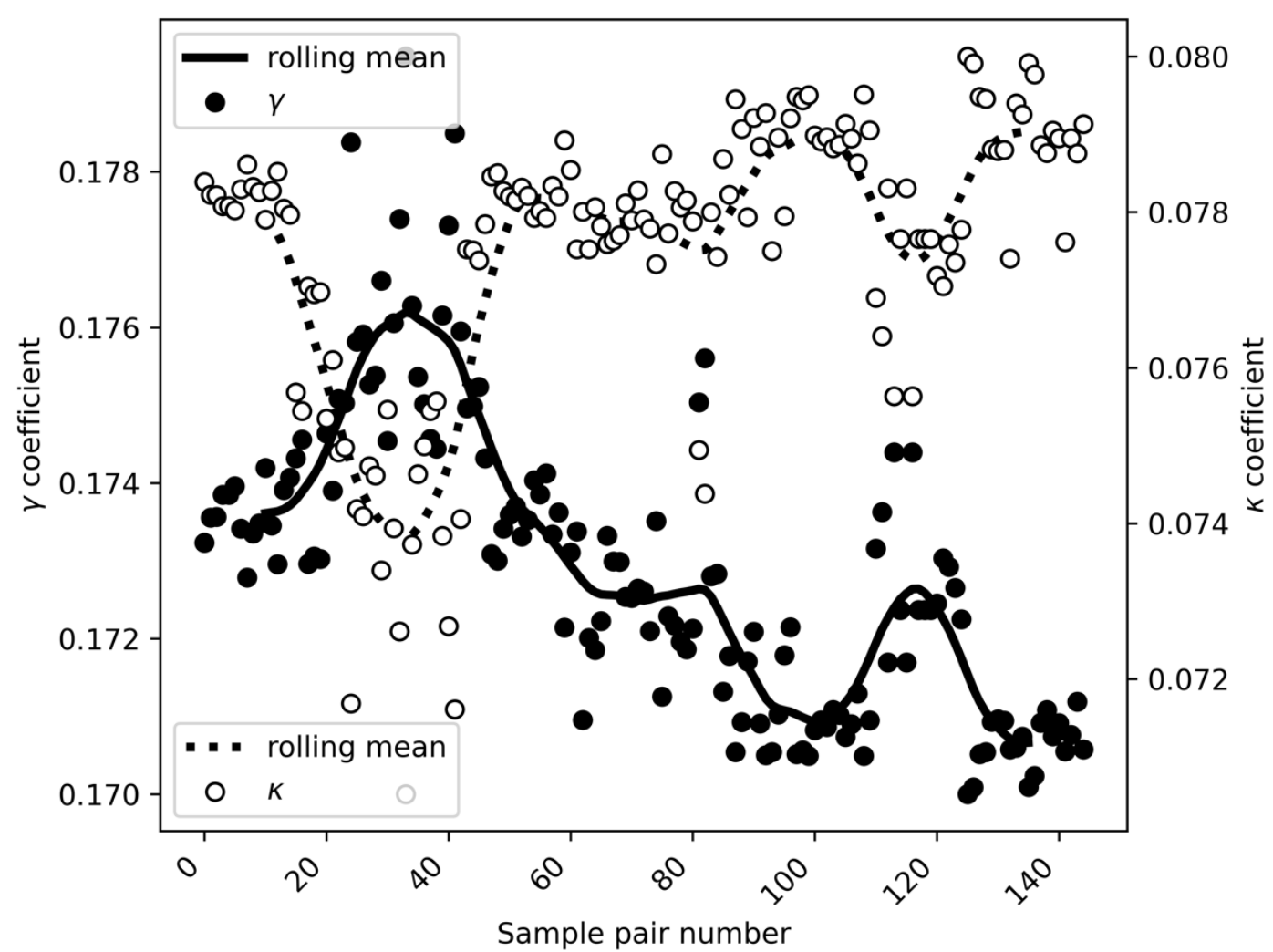

874 Figure 3. Scrambling coefficients for the Lab 1 IRMS from October 2018 to January 2021.

875

876

877

878

879
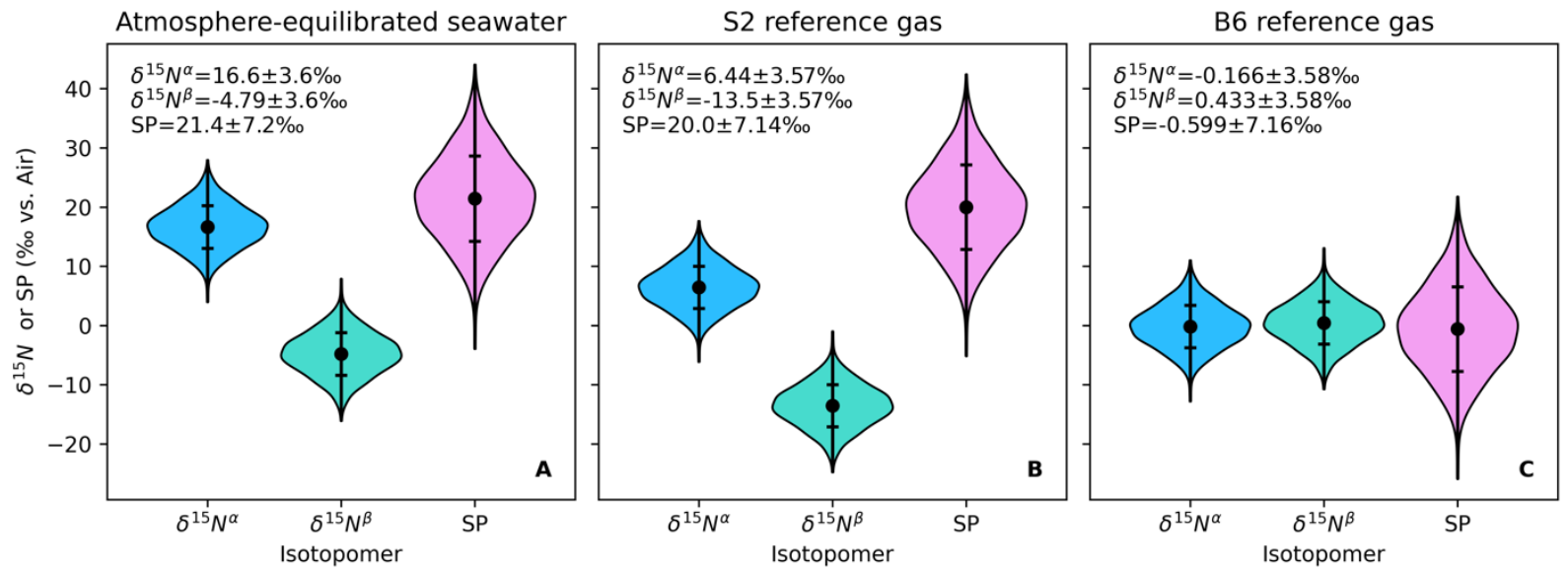

881

Figure 4: Isotopocule values and error associated with an uncertainty of \pm 0.00192 in $\gamma$ and

882 Individual pairs of scrambling coefficients, calculated from individual pairs of reference materials, are shown as a scatter plot. A rolling mean with a 20 -value window (roughly equivalent to one week of analysis) is plotted for each coefficient. The $\mathrm{x}$-axis is sample pair number, rather than date, to better visualize short-term variability. \pm 0.00184 in $\kappa$, based on Monte Carlo simulation results. The violin plots are based on a kernel 
883 density estimate of the distribution and the values plotted and reported on each figure show the 884 mean value $\pm 1 \sigma$.

885 


\section{Supplementary material \\ pyisotopomer: A Python package for obtaining nitrous oxide isotopocules from isotope ratio mass spectrometry}

Colette L. Kelly, ${ }^{1 *}$ Cara Manning, ${ }^{2}$ Claudia Frey, ${ }^{3}$ Noah Gluschankoff, ${ }^{1}$ and Karen L. Casciotti

1. Stanford University, Department of Earth System Science, Stanford, CA 94305, USA

2. University of Connecticut, Department of Marine Sciences, Groton, CT 06340, USA

3. Department of Environmental Science, University of Basel, Basel, Switzerland.

* Correspondence to: Colette L. Kelly (clkelly@stanford.edu). 
Table S1: Different pairings of reference materials. Pooled standard deviations of $\gamma$ and $\kappa$ calculated from different pairings of reference materials, and the corresponding pooled standard deviations of $\delta^{15} \mathrm{~N}^{\alpha}, \delta^{15} \mathrm{~N}^{\beta}$, and SP, are shown for tests performed on the Lab 1 and Lab 2 IRMS. Pooled standard deviations are also shown for scrambling and isotopomer calculations done in the MATLAB and Python versions of the software.

\begin{tabular}{|c|c|c|c|c|c|}
\hline \multirow[b]{2}{*}{ Test } & \multicolumn{5}{|c|}{ Pooled standard deviations } \\
\hline & $\begin{array}{c}\gamma \\
(\% \text { uncertainty*) }\end{array}$ & $\begin{array}{c}\kappa \\
(\% \text { uncertainty*) }\end{array}$ & $\begin{array}{c}\delta^{15} N^{\alpha} \\
\left(\% \text { vs.Air } N_{2}\right)\end{array}$ & $\begin{array}{c}\quad \delta^{15} N^{\beta} \\
\left(\% \text { vs.Air } N_{2}\right)\end{array}$ & $\begin{array}{c}\mathrm{SP} \\
\left(\% \text { vs.Air } N_{2}\right)\end{array}$ \\
\hline Lab 1 three ref. pairings, no extreme values & 0.39 & 0.16 & 0.47 & 0.44 & 0.91 \\
\hline Lab 2 three ref. pairings, incl. extreme values & 0.77 & 1.17 & 2.54 & 2.29 & 4.83 \\
\hline Lab 2 one ref. pairing, excl. extreme values & 0.15 & 0.61 & \multicolumn{3}{|c|}{ (see section 4.7 for precision between replicates) } \\
\hline MATLAB vs. Python & 0.44 & 0.93 & 0.028 & 0.026 & 0.054 \\
\hline
\end{tabular}

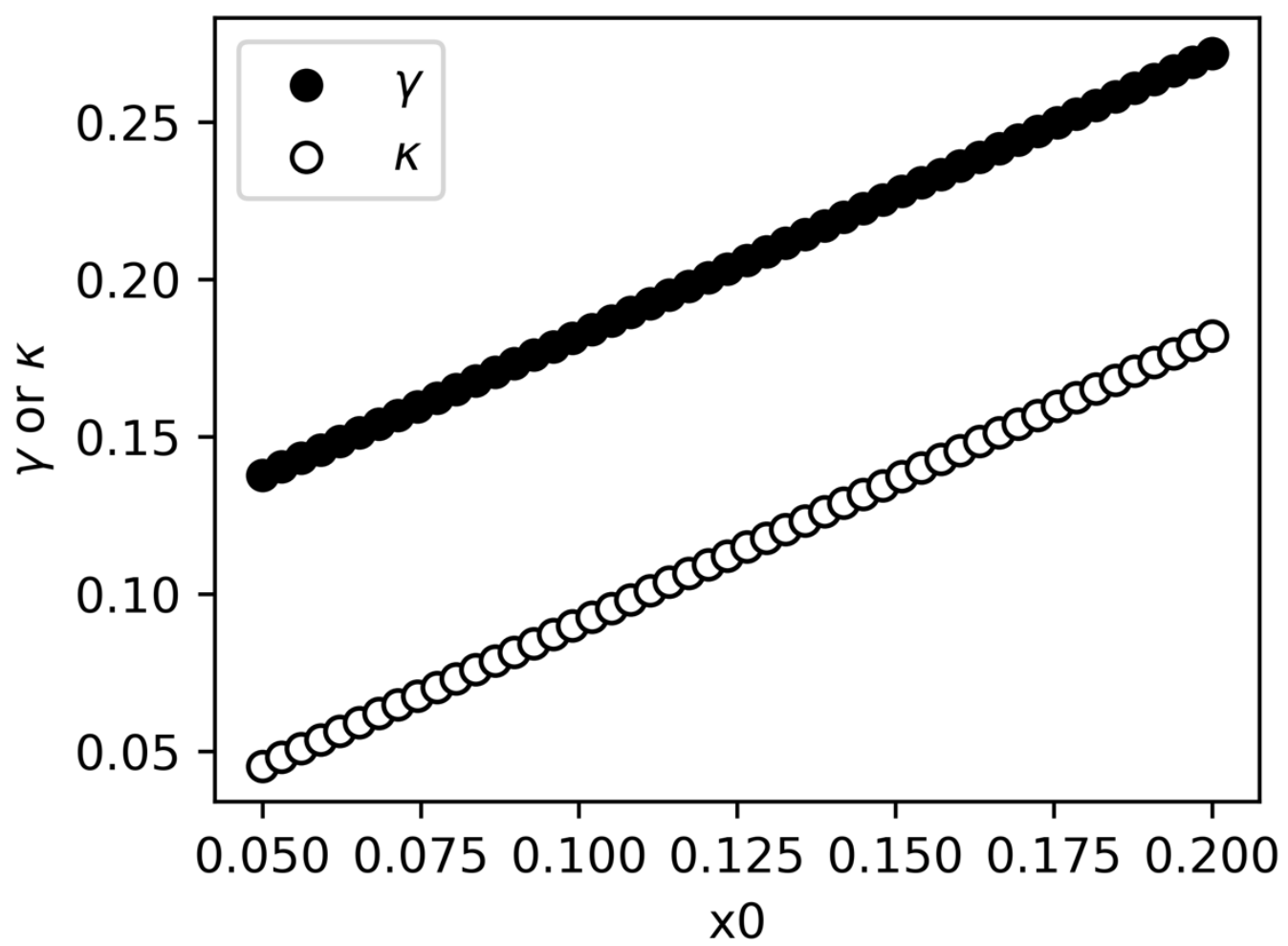

Figure S1. Solutions for $\gamma$ and $\kappa$ calculated across a range of initial guesses $(\mathrm{x} 0)$ for the least squares solver function at the core of pyisotopomer. The default values for $\mathrm{x} 0$ are $\gamma=0.17$ and $\kappa=0.08$, based on the performance of the ThermoFinnigan Delta $V$ mass spectrometer at Lab 1. 

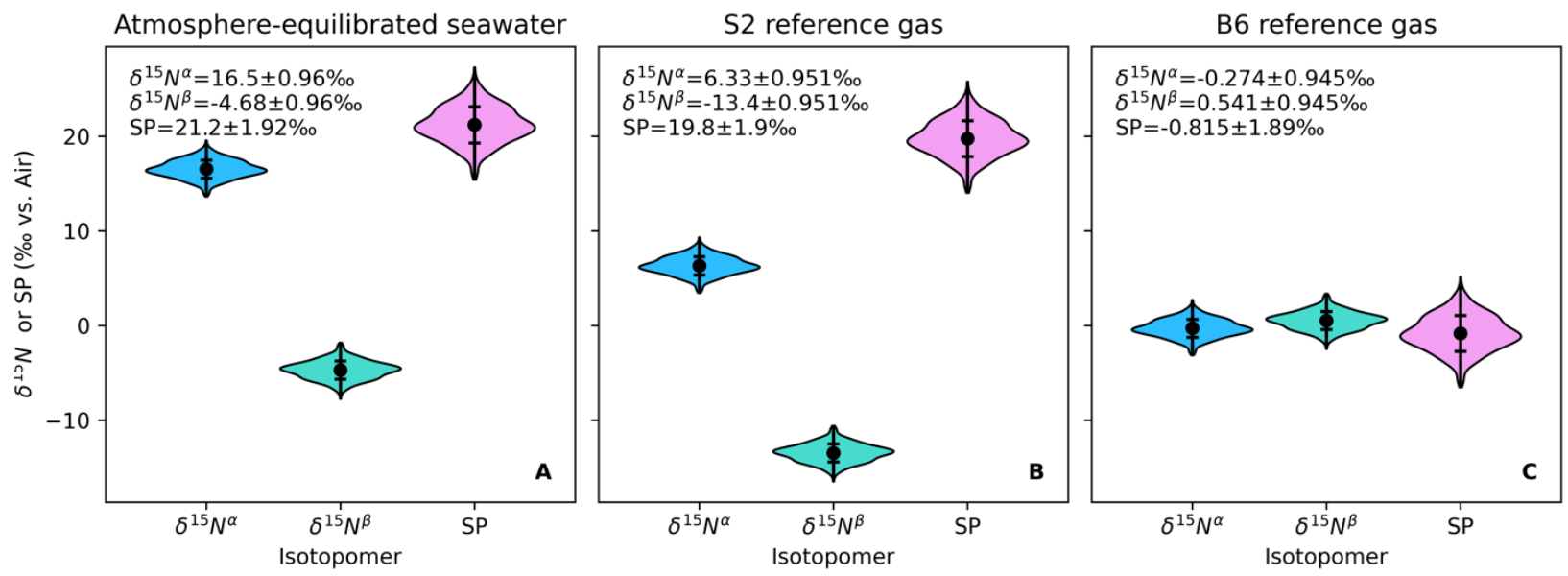

Figure S2: Isotopocule values and error associated with an uncertainty of $\pm 6.83^{*} 10^{-4}$ in $\gamma$ and $\pm 1.48^{*} 10^{-4}$ in $\kappa$, based on Monte Carlo simulation results. The violin plots are based on a kernel density estimate of the distribution and show the mean value $\pm 1 \sigma$. 


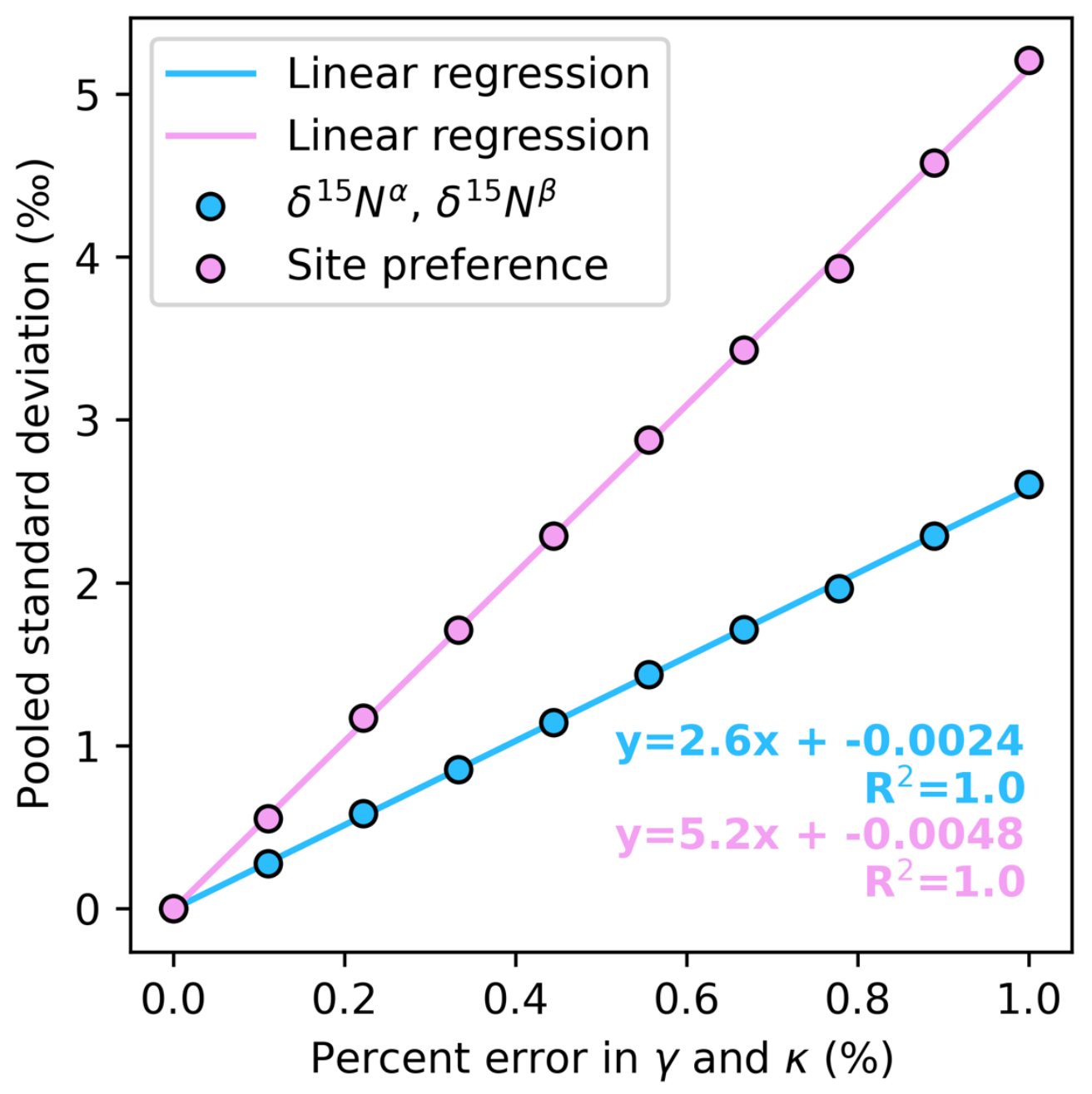

Figure S3: Pooled standard deviation of $\delta^{15} \mathrm{~N}^{\alpha}, \delta^{15} \mathrm{~N}^{\beta}$, and SP resulting from increasing relative uncertainties in $\gamma$ and $\kappa$. Each point corresponds to 1,000 values of $\gamma$ and $\kappa$ sampled from a distribution with standard deviation equal to the given level of uncertainty, and the corresponding pooled standard deviation of 1,000 simulated values of $\delta^{15} \mathrm{~N}^{\alpha}, \delta^{15} \mathrm{~N}^{\beta}$, and SP. 


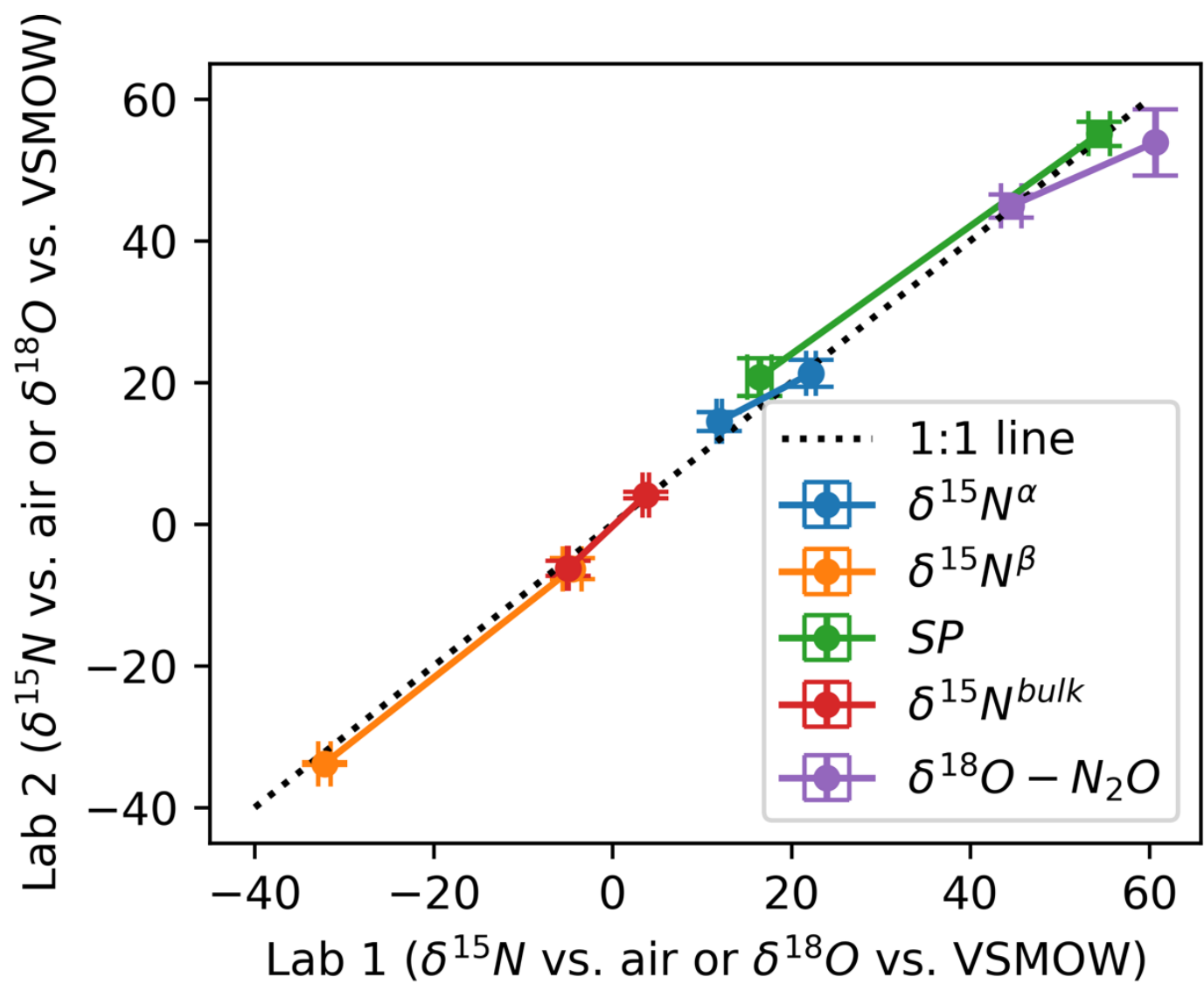

Figure S4: Intercalibration results for lake water unknowns taken at 10 meters and 90 meters depth from lake Lugano in Switzerland. Independent measurements of the isotopic composition of $\mathrm{N}_{2} \mathrm{O}$ in each sample, performed by Lab 1 and Lab 2, respectively, are plotted against each other. Data points represent the mean from replicate bottles taken at the same depth $(\mathrm{n}=2-5)$ and error bars represent one standard deviation. A one-to-one line (black dashed line) is plotted for comparison. 